\section{Salud pública e Imperio en la España Isabelina (1833-1868): el caso de la sanidad militar}

\section{Public health and} empire in Isabellin Spain (1833-68): the case of military health

Francisco Javier Martínez Antonio

Laboratoire REHSEIS Paris

San Antonio María Claret $271^{\circ} \mathrm{C}$

50005 Zaragoz - España

pacoalemania@yahoo.com
MARTÍNEZ ANTONIO, F. J.: Salud pública e Imperio en la España Isabelina (1833-1868): el caso de la sanidad militar.

História, Ciências, Saúde - Manguinhos, v. 13, n. 2, p. 439-75, abr.-jun. 2006.

Este trabajo plantea la consideración de los imperios como unidades socio-históricas básicas para el estudio de la historia de la ciencia, la medicina y la tecnología. Para ello se empieza por desarrollar algunas claves historiográficas y conceptuales desde las cuales modificar el concepto habitual de imperio en un sentido más simétrico, transversal y relacional. Sobre esta base, se estudia la articulación de la salud pública en el Imperio español en el periodo 1833-1868, en concreto, de una de sus ramas: la sanidad militar. El resultado es una imagen más compleja de la misma donde se revelan conexiones transimperiales, la

heterogeneidad y apertura de los espacios metropolitano y colonial y la iniciativa de distintos grupos y territorios al margen de la legislación y discursos oficiales.

PALABRAS CLAVE: historia; salud pública; imperio español; siglo XIX; sanidad militar.

MARTÍNEZ ANTONIO, F. J.: Public health and empire in Isabellin Spain (1833-68): the case of military health.

História, Ciências, Saúde - Manguinhos, v. 13, n. 2, p. 439-75, Apr.-June 2006.

The article analyzes the relations between public health and empire in Spain under the reign of Isabel II (1833-68). After presenting certain conceptual notions, the case of military health is proposed as a specific example of these relations. On a journey through the Empire's different settings (the Iberian peninsula, Cuba, Porto Rico, and the Philippines), the text explains the role played by different groups, often marginalized from historical accounts.

KEYWORDS: history; public health; Spanish empire; nineteenth century; military health. 
* Este trabajo ha sido realizado en el marco de una beca postdoctoral del Ministerio de Educación y Ciencia Ref EX2005-060. Querría agradecer al Dr. Josep Danón, responsable de la Fundación Uriach 1838, su ayuda para obtener algunas de las imágenes $\mathrm{y}$ referencias bibliográficas que figuran en este artículo.

\section{En busca del imperio}

E l presente trabajo se inscribe en una línea de estudios históricos sobre 'medicina e imperio' que ha comenzado a plantearse desde mediados de los años 90. Esta línea es continuadora de otras como 'medicina colonial', 'medicina e imperialismo' o 'estudios postcoloniales' sobre medicina que, a lo largo de las últimas décadas, han generado una producción historiográfica abundante y rica en enfoques diversos $\mathrm{y}$, en ocasiones, complementarios. La continuidad viene dada por el hecho de que, de alguna manera, los estudios sobre 'medicina e imperio' pretenden abordar algunos de los problemas nucleares que no han podido resolverse adecuadamente en dicha historiografía, especialmente los inherentes a la dicotomía centro-periferia o metrópoli-colonia, al carácter de la 'ciencia colonial' o a la interacción entre los saberes y prácticas europeos y extra-europeos. A nuestro entender, las nuevas investigaciones podrían poner las bases de una nueva fase historiográfica, un nuevo 'paradigma' podría decirse con términos de Thomas S. Kuhn, si dicho concepto no estuviera lastrado por la multiplicidad de usos que se le han dado.

La búsqueda de un 'marco imperial' en el que analizar unitariamente las relaciones metrópoli-colonias constituye uno de los aspectos que definen este impulso renovador. En realidad, se trata de un proyecto no específico de la historia de la medicina, sino generalizado en las ciencias sociales y humanas. Así, en la monografía Tensions of empire, editada en 1997 por Frederick Cooper y Ann Laura Stoler, ambos autores consideraban que un objetivo preferente de las agendas de investigación en los cultural studies debía ser "estudiar los imperios a lo largo del tiempo, en la relación de unos con otros y en la relación con sus partes integrantes". Para ello había que "tratar metrópoli y colonia en un único campo analítico, abordando el peso que se da a las conexiones causales y la relevancia de la iniciativa en sus diferentes partes". Ambos autores reconocían que "identificar las reverberaciones sociales y políticas entre colonia y metrópoli es una tarea difícil" (Cooper \& Stoler, 1997, p. 1, 4).

Más específicamente para la historia de la medicina, Warwick Anderson se lamentaba, en una reseña-ensayo publicada en 1998, de la exportación inconsciente del marco estatal-nacional al estudio de la medicina colonial. En su opinión, se había producido en éste la "exitosa construcción de un enclave disciplinario de historiadores de la medicina implícitamente nacionalistas". Para Anderson, "si la historia de la medicina colonial fue una vez la historia de las ideas derivadas de Europa, hoy en día es más probable que constituya una historia de las formaciones sociales derivadas de Europa" (Anderson, 1998, p. 523, 528). En otra reseña publicada 
en 2003, Anderson recogía las propuestas de Cooper y Stoler al afirmar que "necesitamos eventualmente plantear cómo estudiar la medicina colonial, y otros proyectos imperiales, con mayor simetría discursiva e inclusividad, para poner 'centro' y 'periferia' en el mismo marco analítico" (Anderson, 2003b, p. 405).

Recientemente, en un monográfico de la revista Isis, varios reconocidos historiadores de la ciencia y la medicina en las colonias como Mark Harrison o Michael Osborne reflexionaban en el mismo sentido. Para Harrison, su trabajo pretendía principalmente, "plantear ciertas preguntas sobre el marco analítico en el que la ciencia colonial ha sido tradicionalmente considerada, destacando las interacciones con las tradiciones científicas indígenas y el uso de modelos de red para comprender las relaciones científicas dentro y más allá de los contextos coloniales" (Harrison, 2005, p. 56). En su opinión, el término 'ciencia colonial' podría haber constituido "poco más que una etiqueta de conveniencia, careciendo de definición precisa y con una utilidad cuestionable" (Harrison, 2005, p. 63). Por último, un trabajo colectivo de historia de la ciencia editado por Benedikt Stuchtey, en 2005, llamaba a "las historiografías nacionales a incorporar el factor imperial en sus historias", señalando que "las naciones europeas emergieron, al menos en parte, en el contexto de sus proyectos coloniales/imperiales y que los movimientos coloniales fueron simultáneamente conformados por conflictos y acontecimientos de Europa" (Stuchtey, 2005, p. 30-1).

A pesar de las exhortaciones en este sentido, las dificultades de un estudio a escala imperial son evidentes. La idea de estudiar la sanidad en toda la extensión de un imperio concreto, como se plantea en este artículo, podría parecer a primera vista temeraria, no solo por la necesaria brevedad que aquí se impone. Quizás no lo es tanto en el caso del Imperio español del siglo XIX, pero sí por ejemplo si se realizara un trabajo sobre el Imperio español clásico o sobre los imperios británico o francés modernos. No obstante, la cuestión no es tanto la exhaustividad de la posible investigación (todo estudio histórico, incluidas las historias locales o las micro historias, son siempre susceptibles de un mayor aporte de datos) como la identificación de los problemas propiamente específicos de un enfoque imperial. Esto requiere esencialmente un esfuerzo de definición sintética que no va en perjuicio de posteriores énfasis en una $u$ otra dimensión particular que permitan la necesaria $y$ deseable ampliación del aporte documental de todo tipo.

Dicho esto, cabría precisar que los estudios de ámbito imperial en el sentido que se acaba de precisar son todavía escasos en la historia de la salud pública o para el Imperio español. En el primer caso, se ha ido dando un mayor protagonismo a las colonias en las discusiones sobre campañas sanitarias, políticas de salud o modelos 
asistenciales, como se puede comprobar comparando dos monografías clásicas de este campo como las de George Rosen y Dorothy Porter (Rosen, 1958; Porter, 1999a). Creemos que un tema fundamental para situar la problemática imperial en la salud pública es la medicina tropical, donde se han estudiado recientemente aspectos cruciales como la circulación de saberes y profesionales o la construcción del 'blanco' (Bashford, 2000; Haynes, 2001; Anderson, 2003b).

Respecto al Imperio español, los trabajos de Antonio Lafuente, Juan Pimentel y Jorge Cañizares-Esguerra sobre la ciencia en el periodo clásico hasta el siglo XVIII constituyen una referencia destacada, pero aguardan más aportaciones (Lafuente, 2000; Pimentel, 2000; Cañizares Esguerra, 2003, 2005). Sobre el siglo XIX, los estudios son aún más escasos (Elena \& Ordóñez, 2000). En la historia de la salud pública, la única referencia es la monografía sobre paludismo en la España metropolitana y colonial del siglo XX encabezada por Esteban Rodríguez Ocaña (Rodríguez Ocaña et al., 2003). Nuestra tesis de doctorado trató de plantear el tema de forma verdaderamente explícita (siquiera de forma preliminar) para mediados del siglo XIX (Martínez Antonio, 2005a), un acercamiento que pretende profundizarse aquí.

En esta carencia de trabajos para el caso español puede haber influido el sentido ideológicamente sesgado que se dio al término 'imperio' en la historiografía del periodo franquista. También el propio hecho histórico de que la 'edad del imperio' (Hobsbawm, 1988) coincidiera precisamente con el ocaso de España como potencia colonial, lo que creó dificultades de comparación con otros casos. Así, por ejemplo, dependiendo del autor que se consulte, el Imperio español terminó a principios del siglo XIX con la pérdida de la América continental, en 1898, con la de Cuba y Filipinas, o en 1976 con la retirada del Sahara Occidental. En nuestra opinión, convendría superar estas prevenciones en favor del planteamiento de nuevas perspectivas sobre el campo "medicina/ciencia/tecnología en el Imperio español", asumiendo sus paralelismos esenciales con los casos de otros imperios europeos y extra-europeos.

\section{Salud pública e imperio. Elementos de análisis.}

\section{El lugar de la sanidad militar en el Imperio español}

Dada la necesaria brevedad, no es posible una argumentación profunda de la perspectiva analítica que se va a emplear en este trabajo. Por ello, vamos a hacer simplemente algunas precisiones sobre los conceptos 'imperio' y 'salud pública' y sobre la elección de la sanidad militar como objeto de estudio. Por imperio entendemos, en primer lugar, más que un status político o social formal- 
mente reconocido en ciertas sociedades occidentales en un periodo concreto, una relación de dominación de dichas sociedades sobre otras no occidentales. En el caso de Francia, por ejemplo, el Imperio y el Segundo Imperio fueron periodos históricos concretos del siglo XIX pero el imperialismo y el imperio francés existieron fuera de ellos durante todo el siglo. En el caso de España, la independencia de las colonias americanas continentales no implicó que el imperio desapareciera, aunque quedara muy reducido en su tamaño e importancia.

En segundo lugar, el imperio no son las colonias sino la metrópoli más las colonias. Habitualmente, se dice que el imperio británico o francés abarcaba tantos miles de kilómetros cuadrados o tantos millones de personas, pero estos cálculos suelen dejar fuera a Gran Bretaña y Francia propiamente dichas. Por el contrario, el imperio en su conjunto debería ser considerado como la unidad básica de análisis de los acontecimientos históricos (Kamen, 2003). Esto terminaría con la práctica habitual de estudiar los fenómenos históricos por un lado en la metrópoli europea y por otro lado en sus colonias (generalmente en cada una de ellas por separado). Ahora bien, no se trata de hacer una mera yuxtaposición de metrópoli y colonias sino de superar de alguna manera esta dicotomía. En concreto, habría que considerar ambas formaciones como resultado provisional y cambiante de una determinada interacción o relación transimperial que debería convertirse en el objeto preferente de la investigación.

Por un lado, el carácter relacional del imperio, que, en expresión de Bruno Latour, es sistemáticamente 'depurado' de los relatos explicativos (Latour, 1997, p. 106), implica considerar que tanto la metrópoli como las colonias tienen iniciativa, son capaces de provocarse transformaciones mutuamente y evolucionan de forma simultánea. Por supuesto, esta perspectiva no pretende afirmar que el resultado de dicha interacción sea la igualdad o el equilibrio entre metrópoli y colonias, de ahí la definición de imperio en el sentido de dominación, pero por principio considera tanto a las sociedades occidentales como a las no occidentales como realidades humanas esencialmente semejantes y comparables. Por otro lado, el carácter transimperial de la relación implica descomponer la esencialidad de metrópolis y colonias en favor de la consideración de redes, lo que permite dar cuenta de una mayor pluralidad de actores y al mismo tiempo valorar su traslocación a través del imperio. Esto no implica que no haya una tendencia a la confluencia de redes y la subsiguiente definición de un espacio metropolitano y unos espacios coloniales cerrados y homogéneos en sí mismos y separados entre sí, pero en todo caso dicha tendencia nunca sería completa.

Por último, un imperio no existe en el vacío sino en relación con otros imperios. En dicha relación, algunos tienden a adquirir 
una posición predominante y otros, subordinada. En este último caso, la relación transimperial propia de un imperio tiende a debilitarse y tanto su espacio metropolitano como sus espacios coloniales se hacen explícitamente abiertos y heterogéneos. Dependiendo del grado de debilidad, este imperio es influido, intervenido, asimilado o incluso aniquilado por otro. En una perspectiva temporal de larga duración, podría considerarse que la competición entre imperios habría reducido sucesivamente el número de los mismos hasta acabar por formarse uno único de escala planetaria.

Respecto al concepto de salud pública, podría considerarse en un sentido muy general como "las acciones colectivas relativas a la salud de las poblaciones" (Porter, 1999b, p. 14). De forma más concreta y en relación con el concepto de imperio podría decirse, sin embargo, que la salud pública es la dimensión de los imperios relativa a la salud y la enfermedad colectivas. Igual que existe un estado imperial, una economía imperial, una cultura imperial o una política imperial también habría una salud pública imperial. Desde este punto de vista, la historia de la salud pública imperial sería solo una versión específica de la historia imperial, en el sentido de que todas las cuestiones y problemas del imperio se presentarían en su ámbito, como en cualquier otro. No hay una historia general del imperio si no es un conjunto de historias que comparten el mismo planteamiento común y por ello pueden iluminarse o traducirse entre sí.

Dicho esto, creemos que es necesaria una segunda ampliación del concepto de salud pública. Normalmente, éste tiende a designar exclusivamente su realidad 'civil' y, dentro de ésta, a concentrarse en su aspecto 'interior'. La historia de la salud pública ha concedido atención preferente a los Ministerios de Sanidad, a las luchas políticas y sociales por el modelo de sistema sanitario, a las epidemias de las ciudades y del campo, a las investigaciones de las Facultades de Medicina o de las instituciones privadas. Frente a ello, la atención a la sanidad marítima ha sido más bien secundaria; la sanidad de las fuerzas armadas se ha dejado prácticamente en manos de los médicos militares y de la armada con afición a la historia. En nuestra opinión, sin embargo, la salud pública debe incluir también integralmente estos elementos. En el caso del siglo XIX, que es el que aquí se va a tratar, la salud pública se habría ordenado según un doble eje interior-exterior, civil-militar, que habría definido cuatro ramas sanitarias fundamentales: sanidad interior (del territorio), exterior (de puertos y fronteras), militar (del ejército) y naval (de la armada). Estas ramas serían inseparables entre sí y mutuamente condicionadas (Martínez Antonio, 2005a).

Para terminar este punto, trataré de justificar brevemente la elección de la sanidad militar para plantear la problemática imperial 
en el caso español. Durante el periodo isabelino (1833-1868) y, en general, durante todo el siglo XIX, el imperio español se encontró en una posición internacional débil, que reflejaba al mismo tiempo problemas de articulación y una creciente influencia de otros imperios. Tanto en el marco general, como en la salud pública en particular, dicha debilidad era principalmente manifiesta en la pérdida de poder naval (acelerada por la derrota de Trafalgar en 1805) y en la crónica división y enfrentamiento de la sociedad civil, tanto en la península como en las posesiones ultramarinas. Por esta misma razón, los otros dos componentes del estado y de la salud pública, es decir, el componente militar y el componente exterior, que se encontraban en mejor situación, trataron de compensar esas carencias. De ahí que la sanidad militar y la sanidad marítima fueran las dos ramas de la salud pública que tuvieron una dimensión verdaderamente imperial en esa época y sirvan, por ello, para plantear las cuestiones que aquí se quieren tratar.

\section{El marco general de la sanidad militar en el Imperio español (1833-1868)}

Estrictamente, la sanidad militar española se constituyó como tal durante el reinado de Isabel II. Fue entonces cuando cristalizaron las tendencias de organización corporativa, de unificación profesional entre médicos y cirujanos, de vinculación administrativa exclusiva con el Ministerio de la Guerra, de reestructuración territorial, de modernización hospitalaria o de renovación científica y técnica que venían dibujándose desde el último tercio del siglo XVIII. Dejando a un lado el precedente fallido de organización de un 'servicio de sanidad militar' por parte del médico liberal Mateo Seoane durante el Trienio Liberal (1820-1823), fueron los reglamentos de 1836, 1846, 1853 y 1855, junto con algunas disposiciones legislativas complementarias y secundarias, los que establecieron definitivamente la denominación 'Sanidad Militar' para referirse al servicio médico, quirúrgico y farmacéutico del ejército de tierra. El nuevo nombre reflejaba adecuadamente la sustitución del modelo previo de 'policía médica' por uno 'sanitarista', en consonancia con los cambios en la salud pública que tenían lugar por entonces en España, en los principales países europeos y en sus fuerzas armadas (Rosen, 1957; Porter, 1999a; Marset \& Sáez, 1998; Rodríguez Ocaña, 1992, 1994, 2005; Martínez Antonio, 2005a).

A diferencia de otros países, la legislación sanitaria militar elaborada por el Ministerio de la Guerra en Madrid se aplicaba en principio de manera uniforme en toda la extensión del imperio. Ciertamente, a partir del reglamento de 1846, hubo en estos textos legales una sección específica sobre el 'servicio de ultramar' en la que se consignaban ciertas particularidades respecto a la duración 
del destino, la categoría profesional o las obligaciones de los facultativos que diferían del servicio peninsular. Del mismo modo, hubo decretos específicos para la sanidad militar ultramarina, como por ejemplo los que siguieron al informe del Ministerio de Estado sobre los hospitales militares de Filipinas elaborado en 1856 (Regodón, 2002). No obstante, tanto unas como otras disposiciones establecieron básicamente la necesidad de organizar el servicio facultativo del ejército en ultramar de igual forma que se hacía en la península. De esta forma, las famosas y nunca aprobadas 'leyes especiales' para el gobierno de las 'provincias ultramarinas', previstas por vez primera por la Constitución de 1837, tampoco existieron en el ámbito de la sanidad militar (Fradera, 1999).

En consecuencia, el gobierno de la sanidad militar imperial se centralizaba en la Dirección General ubicada en Madrid. Dicha Dirección había sido creada por el reglamento de 1846 para sustituir a la antigua Junta Directiva compuesta por los inspectores médico, cirujano y farmacéutico. Tras unos meses en los que coexistieron tres directores simultáneos, una disposición de 1847 estableció la dirección única y la puso en manos de Manuel Codorniu Ferreras (1788-1857) (figura 1). Sin duda una de las figuras claves de la sanidad militar isabelina, Codorniu asumió su mando oficialmente durante los siguientes ocho años (salvo trece meses entre 1853 y 1854), aunque también lo había hecho de forma oficiosa entre 1837 y 1846 (Guerra, 1973, 1975; Parrilla Hermida, 1980; Calbet \& Corbella, 1981; Massons, 1994). No obstante el prestigio de Codorniu, la Dirección General careció de completa autoridad ejecutiva en los asuntos médico-sanitarios, cuya responsabilidad recaía en última instancia en el Ministro de la Guerra, de forma parecida a lo que sucedía en otros ejércitos europeos (Ring,

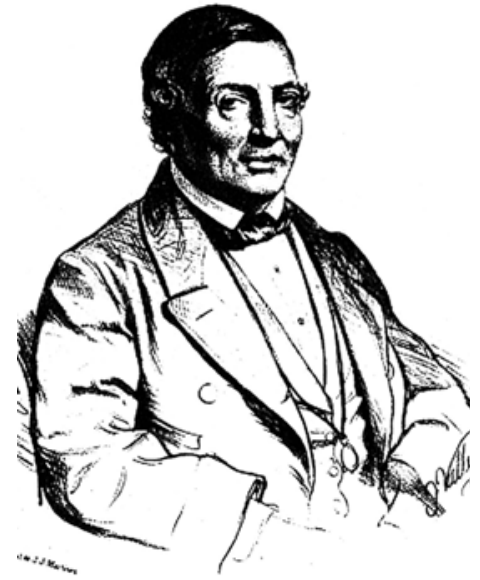

Figura 1 - Retrato de Manuel Codorniu Farreras.

Fuente: Biblioteca Nacional de España. 1962; Lefevbre, 1987; McAllister, 1993; Haynes, 2000). Con el paso del tiempo, la Dirección fue aumentando sus competencias, se dotó una secretaría general y varios departamentos administrativos y, asimismo, de una denominada Junta Superior Facultativa con funciones de asesoramiento en temas profesionales, corporativos y técnicos (Martínez Antonio, 2005a).

Bajo la dependencia del Director General se encontraban los jefes de los distritos de Sanidad Militar en que quedó uniformemente dividido el imperio y que correspondían a los territorios de las Capitanías 
Generales. Aunque hubo pequeñas variaciones en diferentes momentos, desde 1846 se mantuvieron básicamente 17 distritos con sus respectivas capitales: Andalucía (Sevilla), Aragón (Zaragoza), Baleares (Palma de Mallorca), Burgos (Burgos), Canarias (Santa Cruz de Tenerife), Castilla La Nueva (Madrid), Castilla La Vieja (Valladolid), Cataluña (Barcelona), Cuba (La Habana), Extremadura (Badajoz), Filipinas (Manila), Galicia (La Coruña), Granada (Granada), Navarra (Pamplona), Provincias Vascas (Vitoria), Puerto Rico (San Juan) y Valencia (Valencia) (figura 2). En este sentido, la organización de la sanidad militar difería de la civil, con la que tantos paralelismos cronológicos y terminológicos tuvo durante este periodo, ya que ésta última, en su rama interior, se estructuró conforme a la división provincial (49 provincias) establecida por Javier de Burgos en 1833.

Los jefes de los distritos tuvieron categoría de vicedirectores, primero, y subinspectores, más adelante, y dos o tres de ellos integraban, junto con el Director General, la Junta Superior Facultativa. En el siguiente escalón de la jerarquía se encontraban los jefes de los hospitales militares, situados en las capitales de las Capitanías Generales, en las plazas con gobierno militar y, en otras de menor importancia. La red de hospitales militares del imperio, no obstante la disminución del número total por el cierre de centros en pequeñas localidades o heredados de las dos primeras Guerras Carlistas (1833-1840 y 1846-1849), contaba con más de 50 establecimientos, ordenados en cinco 'clases' distintas según su

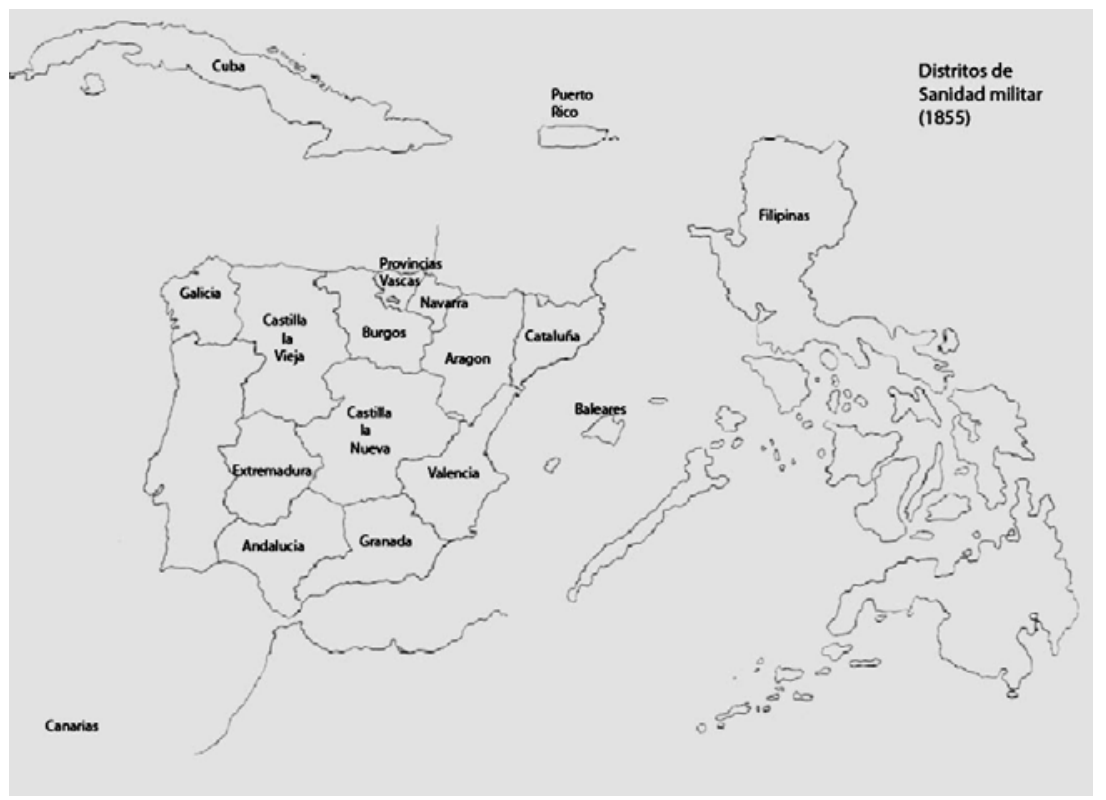

Figura 2 - Mapa de los distritos de Sanidad militar en el Imperio español (1855).

Fuente: Elaboración propia. 
calidad e importancia y complementados por un buen número de enfermerías militares y regimentales, así como por algunos centros instalados provisionalmente en caso de epidemias o de acciones armadas.

Es importante señalar que el Cuerpo de Sanidad Militar constituyó el único cuerpo de funcionarios médicos estatales en el Imperio español hasta la creación del Cuerpo Médico de Vacunadores del Estado en 1885 (Molero \& Jiménez Lucena, 1997). La plantilla teórica pasó de 92 médicos y cirujanos en 1836 a 270 médicos en 1846 y a 372 en 1855, a los que habría que añadir los farmacéuticos, los 'médicos de entrada', y las diversas categorías de 'auxiliares' o 'provisionales'. Al igual que en el ejército en general, hubo una tendencia a la 'macrocefalia' (Busquets, 1984; Puell, 2000), siendo el número de médicos y farmacéuticos desproporcionado en relación con el de enfermeros, practicantes y soldados sanitarios a pesar de la organización de las primeras 'compañías sanitarias' desde 1862 en adelante. Con todo, la 'amovilidad' de los puestos no estuvo totalmente a salvo de injerencias asociadas a alguno de los múltiples vaivenes políticos de la época. En este sentido, es altamente significativo que tanto Manuel Codorniu como su sucesor al frente de la Dirección General, Nicolás García-Briz y Galindo (en 1856-1866), tuvieran una relación personal estrecha con los 'espadones' Baldomero Espartero y Francisco Narváez respectivamente, fraguada en el primer caso durante la Guerra de la Independencia (1808-1814) y, en el segundo, durante la Primera Guerra Carlista.

Por último, en el reglamento de 1855, se preveía la creación de una Escuela de Aplicación de Medicina Militar, siguiendo el ejemplo de la establecida en el Hôpital de Val-de-Grace en Paris, así como de un parque central de material sanitario y un laboratorio central de medicamentos, todos ellos en Madrid. Solo el parque fue creado en 1859 con motivo de la Guerra de África (1859-1860) entre España y Marruecos (Massons, 1994, v. II, p. 219). En cambio, persistió como único laboratorio de medicamentos el existente desde finales del siglo XVIII en Málaga, que había surgido al calor de los sitios españoles de Gibraltar y de los sitios marroquíes de Melilla (Roldán, 1955). En el Hospital Militar de Madrid funcionó desde la década de 1850 un laboratorio histoquímico donde se desarrollaron trabajos de tipo anatomoclínico y en la década posterior comenzó a crearse un museo anatómico por iniciativa del médico Cesáreo Fernández de Losada (Moratinos, 1988).

\section{La Habana, ¿el centro del imperio?}

La distancia existente en España entre las disposiciones legales y la realidad es suficientemente conocida por los historiadores. De ahí que la lectura literal de la legislación al modo del anterior punto 
1 La imbricación entre la elite española en Cuba y el núcleo de poder peninsular ha sido analizada con profundidad en distintas dimensiones por diversos historiadores españoles y cubanos, aunque no estrictamente en términos de imperio. Cf. entre otras, Cayuela Fernández (1993); Moreno Fraginals; Moreno Masó (1993); Moreno Fraginals (1995).

2 Expediente de Fernando Bastarreche Bidot. Archivo General Militar de Segovia (en adelante, AGMS), sección 1, legajo B-1078. Expediente de Nicolás de Tapia y Ureta. AGMS, sección 1, legajo T-128. no permita captar la particular relación existente entre España y Cuba en el siglo XIX, tampoco en el ámbito de la sanidad militar. En nuestra opinión, podría decirse que el núcleo de la sanidad militar española en aquella época estuvo constituido por un eje transimperial Madrid-La Habana, aunque, como se señalará más adelante, esta misma conexión indicaba que ninguna de las dos ciudades cumplía con sus funciones teóricas en sus contextos respectivos español y cubano. ${ }^{1}$ La Habana podría ser considerada en muchos aspectos tan céntrica o más que Madrid en la sanidad militar imperial.

El carácter transimperial del eje Madrid-La Habana comenzó a definirse nítidamente a partir de la década de 1840. Ya se señaló anteriormente que tras la aprobación del nuevo reglamento de Sanidad Militar de 1846 se dio la circunstancia peculiar de existir tres médicos militares con la categoría oficial de director general: Manuel Codorniu, Nicolás de Tapia y Ureta y Fernando Bastarreche Bidot. Estos dos últimos habían tenido un destacado papel en la Primera Guerra Carlista a las órdenes directas de Codorniu, el primero, como secretario de la Subinspección de Medicina y el segundo, como encargado de diversas comisiones técnicas y en acciones de campaña junto a generales como Aldama, el Conde de Luchana o el propio Espartero. ${ }^{2}$ Quizá por razón de su mayor veteranía y prestigio, Codorniu se hizo finalmente con el mando único pero, al mismo tiempo, tuvo que situar a sus dos colegas en puestos acordes con su recién adquirida condición. Tapia continuó de alguna forma su tarea anterior al ser nombrado al frente de la nueva Secretaría de la Dirección. Este puesto se convertiría desde entonces en la auténtica antesala del poder, y probablemente solo la falta de contactos con algún 'espadón' impidió a Tapia suceder a Codorniu en 1856. Por su parte, Bastarreche fue destinado a Cuba como jefe del distrito, cargo en el que habría de permanecer entre 1850 y 1859.

La existencia de un director general al frente de un distrito fue un hecho excepcional y único que simbolizó y dio realidad al mismo tiempo a la centralidad de la Subinspección de Cuba en la sanidad militar imperial. La relación estrecha y la igualdad de categoría entre Bastarreche y Codorniu implicaban la posibilidad de una influencia decisiva de los intereses de Cuba en las decisiones de la Dirección. Por otra parte, a través del capitán general de la isla, José Gutiérrez de la Concha, que permaneció en su cargo durante el mismo periodo 1850-1859, Bastarreche tenía incluso capacidad para influir en el Ministerio de la Guerra en Madrid, independientemente de Codorniu. La estabilidad de su puesto fue mayor que la de éste, ya que no fue privado de su categoría ni subordinado a jefes militares entre 1853 y 1854 . Significativamente, Bastarreche no fue sustituido por un médico enviado expresamente desde la península sino por el secretario de la Subinspección, Ramón Piña 
${ }^{3}$ Reglamento del Cuerpo de Sanidad Militar, 7 de septiembre de 1846. Colección Legislativa de España, 3er trimestre, p. 292-326.

Reglamento del Cuerpo de Sanidad Militar, 12 de abril de 1855. Colección Legislativa de España, $2^{-}$cuatrimestre, $\mathrm{p}$. 348-88.

${ }^{4}$ Real orden aprobando el reglamento para las brigadas sanitarias de la península e Isla de Cuba. Madrid, 6 de junio de 1868. Boletín Oficial de Sanidad Militar, tomo $\mathrm{X}, \mathrm{p}$. 567-97.

5 Reglamento del Cuerpo de Sanidad Militar, 7 de septiembre de 1846. Colección Legislativa de

España, 3er trimestre, p. 292-326.

Reglamento del

Cuerpo de Sanidad

Militar, 12 de abril de

1855. Colección

Legislativa de España,

$2^{\mathrm{o}}$ cuatrimestre, $\mathrm{p}$. 348-88.
Piñuela, creándose así un sistema de 'sucesión' paralelo al que se había establecido en Madrid. Por todo ello, la Subinspección de Cuba y la Dirección General participaban en buena medida de una única posición central, se superponían o confluían en la dirección de la sanidad militar imperial como si la distancia de miles de kilómetros entre ellas virtualmente se diluyera.

La confluencia en el poder entre Madrid y La Habana revelaba, de hecho, una imbricación general entre la sanidad militar peninsular y cubana, en la que la segunda constituyó en muchos aspectos el escenario principal. Como señala Moreno Fraginals, a mediados del siglo XIX, Cuba dejó de ser solo La Habana y Santiago para "mostrar su plena fisonomía insular", con la consiguiente extensión de la red administrativa e institucional a mayores sectores del territorio y la población (Moreno Fraginals, 1995). Este nuevo 'espacio cubano', al excluir sin embargo a los criollos, contribuyó decisivamente a fomentar y justificar la creación del ejército español en general y de la sanidad militar, en particular. Por ejemplo, la plantilla teórica de facultativos se amplió incesantemente desde 22 médicos en 1846 hasta 71 en 1858 y 105 en 1865, aunque en 1867 quedara reducida a 74 (todo ello sin contar con los médicos de entrada, los auxiliares civiles y los 'médicos honorarios'). ${ }^{3}$ En el conjunto de la isla llegó a haber 18 hospitales y 6 enfermerías militares, prácticamente un tercio del total, sin duda la red más importante del imperio (Guerra, 1994). Con motivo de la reorganización de las compañías sanitarias en 1867, se crearon dos brigadas de sanidad militar, una para toda la península y otra solo para Cuba. ${ }^{4}$

Así, para un gran porcentaje de médicos militares peninsulares, el destino en Cuba se convirtió en una etapa más, habitual de su carrera profesional, etapa de la que se podía sacar además un buen rendimiento. Dado que no había ninguna función específica hacia la población cubana nativa ni existían propiamente tropas coloniales, las únicas particularidades del 'servicio de ultramar' en la isla eran la duración mínima de seis años y un sueldo y una categoría algo superiores a sus colegas peninsulares. ${ }^{5}$ Estas condiciones contribuyeron a la cohesión del Cuerpo de Sanidad Militar en su conjunto, ya que un porcentaje importante de facultativos quedaron al margen de las rotaciones y de los movimientos políticos o de campaña del escalafón que eran más frecuentes en la península. Como ventaja añadida, los médicos militares tenían más posibilidades que en la península de hacerse una clientela privada, de trabajar en la beneficencia o de participar en la administración sanitaria civil (Delgado, 1996b). Del mismo modo, también había más opciones de desarrollar las capacidades científicas, al disponerse en general de más medios y de mayor contacto con las novedades de otros países. Entre Cuba y España se dibujó, en definitiva, un espacio de circulación transimperial. 
${ }^{6}$ Real orden reorganizando el servicio sanitario en la Isla de Cuba. Memorial de Sanidad del Ejército y Armada, años 1858-1859, p. 111-4.

7 Real orden dando conocimiento de una de 17 de mayo anterior por la que se reforman las plantillas del personal del Cuerpo en la Isla de Cuba. Boletín Oficial de Sanidad Militar, tomo X, p. 427-30.

8 Para fundamentar esta afirmación y otras posteriores, hemos cruzado datos procedentes de las siguientes fuentes: 'Escalillas de Sanidad Militar' de los años 1853 y 1858 que se encuentran en la Biblioteca del

Servicio Histórico Militar de Madrid; un 'Estado del Personal de Sanidad Militar del Ejército de África' publicado en la revista Memorial de Sanidad del Ejército y Armada en 1859; y

expedientes personales de médicos militares conservados en el Archivo General Militar de Segovia. Además, ha sido muy útil Massons (1994), así como la consulta del catálogo de la Fundación Uriach 1848 y la información proporcionada por su responsable, el doctor Josep Danón.
La centralidad del 'espacio cubano' en la sanidad militar imperial se materializó en ciertas instituciones y organismos que dieron preeminencia a La Habana y a la isla en general. Por ejemplo, el Hospital General Militar de San Ambrosio en La Habana se convirtió probablemente en el mayor y más moderno hospital militar del imperio. El único de $1^{a}$ clase en la isla, llegó a tener una capacidad de mil camas y un equipo técnico de 92 personas (Del Pino, 1963; Massons, 1994; Delgado, 1996b; Ancheta, 2003). Bastarreche realizó allí 'reformas considerables en orden, policía y salubridad' e introdujo a 40 Hermanas de la Caridad para realizar el servicio de enfermería. Hasta la década de 1840, el hospital acogió varias cátedras de la Facultad de Medicina y, posteriormente, se creó un pequeño laboratorio de investigación para el estudio de las principales enfermedades de la isla como el paludismo y la fiebre amarilla. El distrito cubano fue pionero en la creación de una sección de estadística (1851), de un sanatorio antituberculoso, que funcionó durante 1851 en la isla de Pinos bajo la dirección de Ramón Piña Piñuela, y de un hospital o depósito de aclimatación desde mediados de la década de 1840 que varió en diversas ocasiones su localización. De igual forma, en 1858 se dispuso la creación en La Habana de un laboratorio de medicamentos, más de 25 años antes de que funcionara el central de Madrid. ${ }^{6}$ También existió en la ciudad, un parque de material sanitario durante la década de $1860{ }^{7}$ En muchos aspectos, el centro de la sanidad militar española estuvo en La Habana.

\section{Los catalanes en la sanidad militar imperial}

Contrariamente a lo que se suele afirmar en relación con la oficialidad del ejército en general (Clara et al., 1995; Puell, 2000), la participación de catalanes en la sanidad militar isabelina fue muy significativa, especialmente desde finales de la década de 1840. Desde ese momento en adelante, se puede constatar que más de un $30 \%$ de los miembros del Cuerpo de Sanidad Militar eran oriundos de Cataluña, porcentaje netamente superior a lo que le correspondía por su población. ${ }^{8}$ Esto indica que quizás la participación catalana en el ejército español isabelino tuvo lugar preferentemente en los cuerpos técnicos (ingenieros, sanidad militar) más que en las armas generales (infantería, caballería). En cualquier caso, más importante que el número fue la manera en que Cataluña contribuyó a la configuración de la sanidad militar imperial.

Como ya han estudiado algunos autores en relación con la actividad comercial e industrial y la migración, los catalanes constituyeron una red propia dentro del Imperio español isabelino, que no se siempre se ciñó estrictamente a sus límites (Fradera, 1987; Yáñez, 1992; AA.VV., 1995; Enciclopedia Catalana, 1997; Jardí, 1998). 
Esta participación 'diferenciada', nunca regulada explícitamente en la legislación, se dio asimismo en el ámbito de la sanidad militar. La circulación de médicos militares catalanes, aunque dentro del marco general, consiguió definir espacios propios en la península y en ultramar y mecanismos específicos de organización en relación con el eje Madrid-La Habana. Esta relativa autonomía fue la que posibilitó y limitó al mismo tiempo el alcance de la contribución catalana a la sanidad militar isabelina, una contribución que sin duda fue decisiva para su creación y funcionamiento.

Un buen punto de partida para analizar el componente catalán de la sanidad militar es seguir la trayectoria geográfica de los médicos a través de los escalafones y los expedientes personales. Desde finales de la década de 1840, en el ámbito peninsular, se observa una concentración preferente de médicos catalanes en destinos en Cataluña o en territorios de la antigua Corona de Aragón (Aragón, Baleares, Valencia). La dirección de los hospitales militares catalanes pasó progresivamente a manos de facultativos locales y, desde 1858 al menos, la subinspección del distrito fue ocupada por un médico catalán (primero, Joaquim Sayrols i Velat y desde 1860 a 1868, Antoni Martrús i Codina). Respecto al menor número destinado fuera de las zonas citadas, se observa una preferencia por las Provincias Vascas o por distritos 'periféricos' como Canarias, Extremadura y Granada. En el caso de ultramar, los destinos en las Antillas fueron mucho más numerosos que en Filipinas, pero con una distribución particular. En Cuba, los médicos catalanes se concentraron preferentemente, al igual que los emigrantes en general, en ciudades de la mitad oriental de la isla como Santiago de Cuba, Guantánamo y Cienfuegos. Por su parte, Puerto Rico fue un destino especialmente solicitado y médicos catalanes ocuparon a menudo la subinspección del distrito (por ejemplo, Miquel Pinet i Artigalás en 1845-1846 y Jaume Campreciós i Costa en 1846-1852) (Massons, 1994, v. II, p. 151, 171).

Este proceso de 'catalanización' del Principado y de definición de un espacio catalán ultramarino se consiguió a través de un 'ritmo' de circulación menor que el que se daba en el núcleo de la sanidad militar. Esto significaba que, en general, los médicos catalanes bien solían permanecer largo tiempo en sus destinos en Cataluña o alrededores o bien solían emigrar por largos periodos (a veces definitivos) a Cuba y Puerto Rico. Si para los médicos no catalanes los destinos en la península y Cuba eran etapas de una trayectoria profesional, para los catalanes se trataba más a menudo de elegir entre asentarse de forma estable en Cataluña o en ultramar, siendo ésta la manera de asegurar su espacio particular frente a la posibilidad de ser incorporados a la circulación general del imperio. El precio de esta práctica fue seguramente un ascenso más lento en el escalafón del Cuerpo, pero esto se compensó por una mayor 
${ }^{9}$ Expediente personal de Pedro Carreras Pujol. AGMS, sección 1, legajo C1611 . tendencia a compatibilizar el servicio en el ejército con el establecimiento de una clientela privada o con la participación en la sanidad civil o la beneficencia locales.

La mayor tendencia a las actividades fuera del ejército llevaba en ocasiones a desvincularse completamente. No obstante, durante el periodo isabelino, existieron ciertas organizaciones paramilitares o pseudomilitares que hicieron 'atractivo' a un cierto número de médicos catalanes el relacionarse con la institución militar o consiguieron evitar su total desvinculación de ella. Estas organizaciones variaron según el signo político del momento e incluyeron el somatén y las milicias provinciales/cuerpos francos, en Cataluña y los 'voluntarios del comercio' y las 'milicias blancas', en Cuba (Pérez Garzón, 1978; Vallverdú, 1986; González Calleja, 1992; Cayuela, 1993; Moreno, 1995; García Balañá, 2002). En general, estas formaciones irregulares estuvieron asistidas por médicos militares propiamente dichos o por 'auxiliares', 'provisionales' u 'honorarios', los cuales, o bien eran médicos civiles o bien médicos militares alejados o retirados del servicio activo. Dado el carácter local del somatén y de las milicias provinciales de ciudades como Barcelona o Reus y la proporción significativa de catalanes en las organizaciones cubanas, la participación de médicos catalanes debió ser importante.

Dejando a un lado el caso excepcional de Manuel Codorniu, los médicos catalanes no ocuparon los puestos de mayor responsabilidad de la sanidad militar en este periodo. No obstante, consiguieron establecer unos itinerarios jerárquicos propios al margen del eje Dirección General-Subinspección de Cuba. En la Cataluña peninsular, por ejemplo, el Hospital Militar de Barcelona se convirtió en el vehículo para alcanzar la subinspección del distrito, considerada con el tiempo como una especie de 'Dirección General Catalana'. Así, Pere Carreras i Pujol estuvo destinado como médico en el Hospital de Barcelona desde 1842 y ejerció como director del mismo al menos entre 1853 y 1858 (figura 3). ${ }^{9}$ Su larga permanencia en el mayor hospital del Principado le debió convertir en una especie de jefe oficioso de la sanidad militar en Cataluña frente a los cambios periódicos en la subinspección, durante largo tiempo en manos de médicos no catalanes. Cuando en el último año Carreras fue destinado a Granada como jefe de distrito, le sucedió en el cargo Antoni Martrús i Codina, que ya venía trabajando en el hospital al menos desde 1853. Martrús accedió en 1860 a la Subinspección de Sanidad Militar de Cataluña y, entonces, fue sustituido como director por Josep Carles i Martí, otro médico del hospital. En ultramar, pudo darse un fenómeno parecido aunque carecemos de datos precisos al respecto.

La particular implicación de Cataluña en el ejército isabelino contribuyó incluso a la realización de dos pequeñas expediciones 


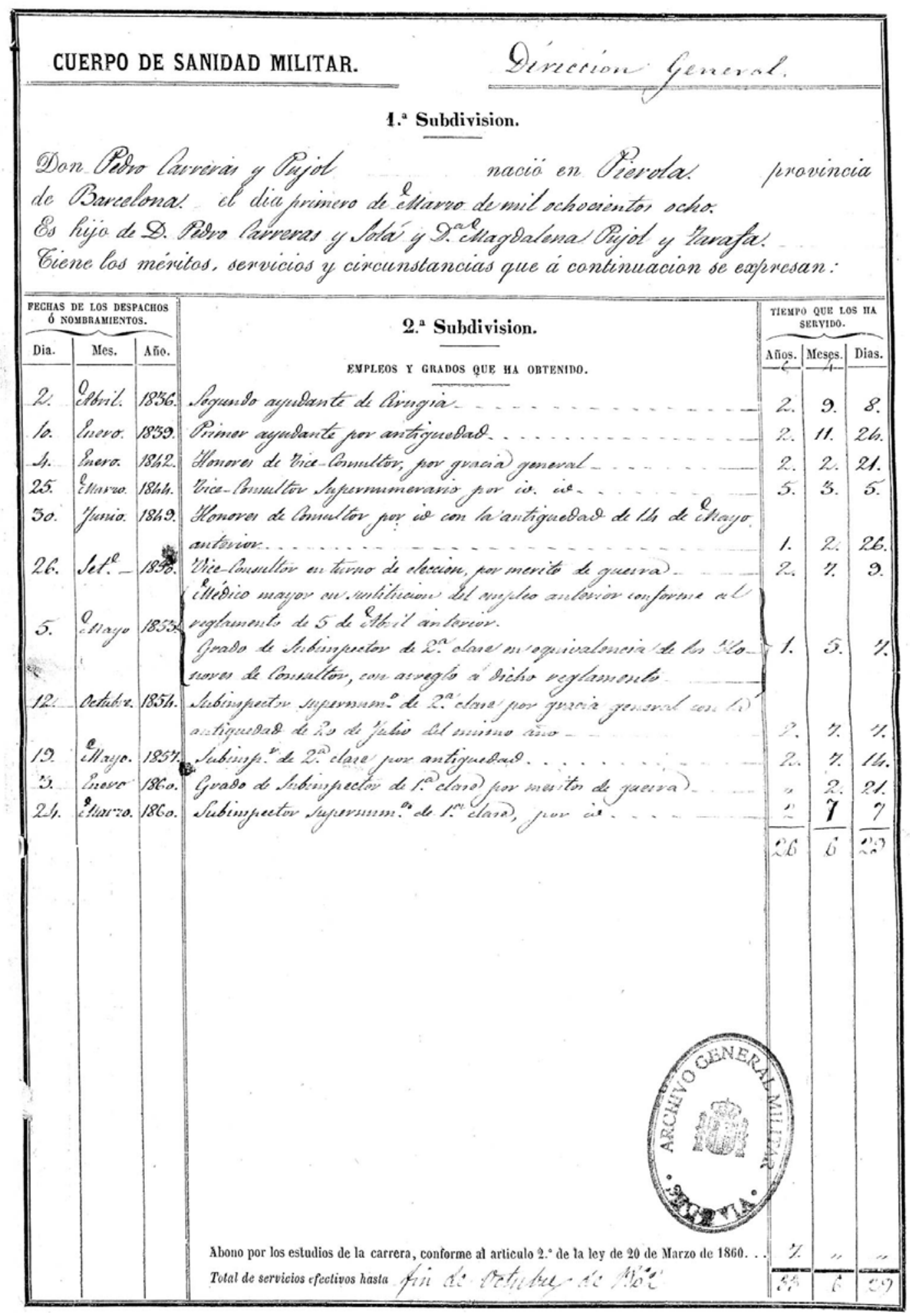

Figura 3 - Portada del expediente personal de Pere Carreras i Pujol. Fuente: Archivo General Militar de Segovia, Sección 1, Legajo C-1611. 
militares durante la década de la década de 1840, en las que la jefatura de sanidad militar recayó en médicos catalanes. En 1848, el entonces capitán general de Puerto Rico, Joan Prim i Prats, sofocó una insurrección en la isla caribeña de Saint Thomas, con el consentimiento de la potencia colonial responsable, Dinamarca (De Diego, 2003). Saint Thomas era en la práctica un 'mercado cautivo' de Puerto Rico y el restablecimiento del orden se hizo en beneficio de los intereses catalanes predominantes en la isla. Por otra parte, en 1849, España decidió enviar una fuerza militar a Italia, en el marco de su participación en la Santa Alianza para restablecer el papado de Pío IX frente a la recién proclamada 'República Romana' (Marín, 2005). De Barcelona partió un ejército expedicionario de unos 10.000 hombres, muchos de los cuales eran catalanes y cuyos responsables sanitarios fueron el ya citado Pere Carreras i Pujol y Joan Faura i Canals, a la sazón director del Hospital Militar de Tortosa (Tarragona). La expedición actuó fundamentalmente en territorio del Reino de Nápoles y, dada la histórica vinculación de esta zona con Cataluña y los objetivos católicos de la misión, debió encontrar amplia acogida entre la Cataluña conservadora.

En definitiva, todos estos hechos muestran que durante el periodo isabelino (especialmente en su última fase) se definió tácitamente una participación diferenciada de Cataluña en la sanidad militar española que, al mismo tiempo, proporcionó una buena dosis de estabilidad al conjunto de ésta. Durante la Primera Guerra Carlista, la sanidad militar hubo de enfrentarse al problema gravísimo que supuso la existencia de un sistema alternativo de alcance cuasi-estatal en las filas del pretendiente Don Carlos. El nuevo modelo sanitarista corrió el riesgo de morir antes de nacer. Por su parte, en Cataluña, la brecha entre las concepciones liberales y tradicionalistas esterilizó durante ese mismo conflicto los intentos de definir una posición particular dentro del conjunto español (o de transformar éste para conseguir esa posición). A través de los desarrollos que tuvieron lugar en décadas posteriores, incluida la creación del 'espacio cubano', se consiguió, en el primer caso, constituir una sanidad militar española relativamente estable (aunque su nivel fuera considerado a menudo insuficiente) y, en el segundo, garantizar un cierto grado de autonomía para los médicos catalanes dentro de la misma (aunque desde ciertos sectores se demandara un grado mayor).

\section{La colonia abierta: médicos criollos, culíes, esclavos negros y la sanidad militar en Cuba}

Como se ha mostrado en los dos apartados anteriores, el 'espacio cubano' fue fundamental para la configuración de la sanidad militar isabelina, al constituirse como parte decisiva del espacio general 
de circulación transimperial de los médicos militares peninsulares y del específico de los catalanes. Por el contrario, resulta evidente que los únicos que no participaban en dicho espacio eran paradójicamente los propios médicos cubanos, aunque a mediados del siglo XIX fuera verdaderamente difícil definir lo que era un 'médico cubano', como lo era definir la 'cubanidad' en general (Moreno Fraginals, 1995). El análisis de este hecho apunta directamente a la insuficiente o débil articulación imperial de la sanidad militar española y por ello debe ser considerado fundamental para entender ésta.

Podría decirse que en un imperio colonial moderno 'típico' la transimperialidad metropolitana debía ser un fenómeno con una serie de características muy particulares. Por ejemplo, la metrópoli debía actuar como suministradora unificada y única de personal a las colonias. Es decir, la circulación de personal metropolitano debía hacerse por vías institucionales comunes y con criterios uniformes y no debía haber otros circuitos paralelos hacia las colonias desde otros países. Además, el número de este personal debía ser relativamente modesto; su circulación, lenta, caracterizada por estancias de larga duración; la libertad de acción respecto a las directrices metropolitanas, amplia. Una conexión transimperial con esta estabilidad era causa y resultado, por un lado, de la definición de un espacio metropolitano cerrado y homogéneo, de la subordinación dentro del mismo de estructuras locales o sub-estatales y de la capacidad de expansión del conjunto hacia sociedades vecinas. Por otro lado, también se asociaba a la definición de espacios coloniales cerrados y homogéneos, a la subordinación dentro de los mismos de estructuras locales previamente existentes y a la capacidad de expansión del conjunto hacia sociedades vecinas.

En el caso de la sanidad militar española, la circulación hacia Cuba y Puerto Rico no estuvo unificada ya que los médicos militares catalanes establecieron su itinerario particular y, como se verá más adelante, hubo otras zonas como las Provincias Vascas que participaron muy por debajo de sus posibilidades. Pero tampoco fue una circulación única, ya que, por ejemplo, se estableció una red de médicos cubanos criollos entre Cuba y diversos países europeos, Estados Unidos o Venezuela. En vista de las circunstancias que se daban en la isla, muchos médicos criollos se formaron en París, Londres o Nueva York o viajaron allí para adquirir nuevos conocimientos y técnicas. De ahí que, en muchos aspectos, su nivel fuera mayor que el de los españoles y que varios de ellos llegaran a adquirir prestigio internacional en sus especialidades. (Massons, 1994; Moreno Fraginals, 1995; Delgado 1996a). Un cierto número se estableció en aquellos países precisamente por razones profesionales o bien fue obligado a exiliarse por las autoridades españolas. En ambos casos, estos facultativos se incorporaron a menudo a los círculos anexionistas o bien regresaron a Cuba en 
10 En el imperio británico, la duración de las estancias era significativamente mayor, según los casos tratados en Haynes (2001) y Harrison (1996). diversos momentos para participar en levantamientos contra el dominio español.

De muy distinto carácter fue la circulación de médicos chinos, que se asoció a la llegada a la isla de más de 150.000 trabajadores forzados de ese origen desde China y Filipinas (conocidos como coolies o culíes) y de algunos miles de emigrantes previamente establecidos en California (Delgado, 2004). Las instancias oficiales, incluida la sanidad militar, ignoraron sistemáticamente a estos médicos, aunque el grado de desarrollo de la medicina china también hacía difícil su mera asimilación. Por último, la constante introducción de esclavos de raza negra en la isla, aunque frenada a partir de la década de 1840, supuso una conexión transatlántica que incluyó sanadores de diversas sociedades africanas que ocuparon una posición extremadamente marginal. Paradójicamente, estos dos circuitos cuyo control escapaba a las autoridades españolas fueron promovidos por éstas. El objetivo, sin duda, era crear un elemento radicalmente opuesto a los europeizados médicos criollos que impidiera en última instancia la posibilidad de una sanidad independiente.

La imperfecta unidad de la circulación de médicos militares españoles, unida a la existencia de redes que escapaban al control de las autoridades, afectó a la estabilidad de la conexión transimperial. Así, el número de médicos militares peninsulares enviados a Cuba y Puerto Rico fue 'excesivamente' elevado. El ritmo de circulación fue relativamente rápido, dado que la estancia obligatoria fijada por ley era solo de seis años. En Cuba, por ejemplo, hubo al menos tres subinspectores de distrito entre 1846 y 1868 (aunque en el ejército en general fue peor, ya que hubo ocho capitanes generales en el mismo periodo). ${ }^{10}$ En cuanto a la libertad de acción, fue reducida, pues el desarrollo de la sanidad militar se enmarcó en el modelo de la legislación y de las instituciones peninsulares, aunque los resultados fueran en ciertos aspectos mejores que en la península.

Como consecuencia de la referida inestabilidad, la incapacidad de establecer en Cuba una sanidad militar colonial equiparable a la que aplicaban otras potencias europeas en algunos de sus territorios ultramarinos fue manifiesta. En primer lugar, el 'espacio sanitario' de la isla careció de homogeneidad y de cierre. Como ya se señaló anteriormente, los médicos catalanes tenían una particular implantación geográfica, que se prolongaba además hacia Puerto Rico y una mayor tendencia a dedicarse al ejercicio privado. Cabría señalar además las diferencias entre los equipamientos de la mitad occidental y los de la mitad oriental de la isla, así como la débil continuidad de las estructuras sanitarias entre ambas. En definitiva, todo ello hacía que la nueva 'fisonomía insular', también en el caso de la sanidad militar, fuera menos plena de lo que sugiere Moreno Fraginals. 
En segundo lugar, hubo una manifiesta incapacidad de la sanidad militar española para integrar subordinadamente las estructuras locales, aunque por razones bastante contrapuestas. En el caso de los médicos criollos, se daba la paradoja de que su formación, su equipamiento o su nivel de ingresos eran mejores y mayores de los que les podía proporcionar la sanidad militar. Si hubieran participado en ésta, su lugar habría estado en la oficialidad $\mathrm{y}$ en posiciones de responsabilidad, algo que, evidentemente, no podían admitir las autoridades españolas. Por el contrario, la falta de integración de médicos chinos y sanadores de raza negra era debida a su marginación sistemática y a su exclusión de la sociedad cubana respectivamente. Del mismo modo que no se crearon en Cuba tropas coloniales con oficialidad española y soldados negros o chinos, no se dio tampoco una situación en la que se combinaran con diferencia jerárquica médicos españoles y personal auxiliar de estas etnias (practicantes, enfermeros, sanitarios), como habría podido hacerse por ejemplo en la brigada sanitaria.

Por último, las expectativas de ofrecer a una posible sanidad militar colonial una expansión interna o externa eran mínimas. Respecto a lo primero, las medidas tomadas en el breve periodo 1853-1854, en el que se crearon en Cuba las milicias blancas y se restablecieron los batallones de 'pardos y morenos', tuvieron un carácter más bien simbólico por lo pequeño de su alcance y por no profundizarse posteriormente. Su repercusión en la sanidad militar debió ser irrelevante. En el segundo caso, el contexto internacional en el Caribe y en el continente americano no favorecía las apetencias españolas frente a otros países europeos, ni las de los europeos frente a las jóvenes repúblicas latinoamericanas y los Estados Unidos. La imposibilidad de expansión pesó también sin duda en la falta de integración de no-españoles en la sanidad militar. No por casualidad, la única ocasión en la que se consiguió incorporar un pequeño número de facultativos y auxiliares criollos fue con motivo de la anexión española de Santo Domingo entre 1861 y 1865 (Massons, 1994, p. 192). De modo semejante, algunos 'negros emancipados' que fueron reclutados en La Habana en 1862 para impulsar la colonización de la isla de Fernando Poo (golfo de Guinea), también se incorporaron a las unidades militares españolas allí existentes y contribuyeron a la creación de un pequeño "asentamiento de aclimatación y recuperación" en dicha isla (De Castro, 1994).

En resumen, la importante presencia directa de la sanidad militar española en Cuba y Puerto Rico constituía en último término un intento de compensación de la inestabilidad de la conexión transimperial. El riesgo de que los médicos criollos organizaran estructuras sanitarias independientes siempre pesó en las autoridades españolas. De ahí su exclusión o exilio, las medidas de 
atracción como la expedición a Santo Domingo o el consentimiento de la presencia de médicos chinos y sanadores africanos que dificultara lo más posible una hipotética colaboración en contra de las autoridades españolas. Con todo ello se logró un equilibrio precario, que no impidió que, a pesar de todo, los diversos grupos comenzaran a colaborar entre sí en el curso de la Guerra de los Diez Años (1868-1878).

\section{La metrópoli abierta: Sanidad militar en las Provincias Vascas y en el Campo de Gibraltar}

La inestable articulación imperial de la sanidad militar española tuvo un reflejo tan patente en la península como en ultramar. En definitiva, ambos hechos eran inseparables. El espacio metropolitano se configuró también como un espacio abierto, heterogéneo, con circulaciones alternativas que no se subsumían en el núcleo general. Dos escenarios representaban especialmente estas características, aunque por razones opuestas: las Provincias Vascas y el Campo de Gibraltar.

Aunque la Primera Guerra Carlista no fue un acontecimiento exclusivamente impulsado por dinámicas existentes en las Provincias Vascas, no cabe duda de que éstas actuaron como uno de sus motores principales. En el ámbito de la sanidad militar, como ya se indicó previamente, los carlistas llegaron a poner en pie en el curso del conflicto un auténtico sistema sanitario militar propio, cuyo núcleo fundamental se localizaba en el denominado 'frente del norte'. Allí, la sanidad del ejército carlista tuvo su propio jefe (primero Teodoro Gelos; luego, Bartolomé Obrador), su propio reglamento (aprobado casi simultáneamente al primer reglamento isabelino de 1836), sus propios hospitales y personal sanitario (Massons, 1994, v. II, p. 106-19). La guerra no terminó en victoria o derrota claras sino en un cierto acuerdo simbolizado por el 'abrazo de Vergara', que inauguraría una etapa de 'excepcionalidad' de las Provincias Vascas dentro del régimen constitucional, incluida la institución militar. Hasta 1876 se conservó una parte sustancial de su régimen foral que incluía, entre otras cosas, el mantenimiento de instituciones de gobierno propias (Juntas Generales, Diputaciones), la exención fiscal y la exención del servicio de armas (Castells, 2003, p. 121).

Después de la guerra, la participación vasca en la sanidad militar española se redujo en todos los aspectos. Los hospitales militares se fueron suprimiendo progresivamente, sobre todo a partir de la década de 1850, quedando limitados a los de Vitoria y San Sebastián. En paralelo, el número de médicos militares vascos disminuyó hasta un porcentaje muy por debajo de lo que habría correspondido a esta zona en términos de población, tanto en des- 
11 Expediente personal de León Anel Sin. AGMS, sección 1, legajo B1787. tinos peninsulares como en ultramarinos. Solo un pequeño número de facultativos que habían actuado en el bando carlista optaron por la 'asimilación' dentro de la sanidad militar constitucional (Massons, 1994, v. II, p. 114-6). La subinspección del distrito fue habitualmente ocupada por subinspectores de $2^{\circ}$ clase, a diferencia por ejemplo de las de Cataluña y Castilla La Nueva, y, generalmente, por médicos originarios de otras áreas (entre otros, León Anel Sin entre 1851 y 1855 y Ángel Saleta Galli hasta 1858 al menos). ${ }^{11}$

Los médicos vascos se decantaron principalmente por la sanidad civil o la práctica privada individual o mutualista. Por ejemplo, en 1836, durante el sitio de Bilbao por el ejército carlista, se fundó en la ciudad el Hospital Civil de Achuri, financiado por el ayuntamiento y la diputación de Vizcaya, que habría de conocer un fuerte desarrollo a lo largo del siglo (Granjel \& Goti, 1983). Pero también hubo un porcentaje de médicos, practicantes o auxiliares que, después de la guerra, optaron por exiliarse en Francia, desde donde regresaron en ocasiones para participar en nuevos levantamientos armados (Massons, 1994, v. II, p. 115). Finalmente la guerra fue un factor fundamental para la primera gran oleada de emigración vasca hacia América en el siglo XIX. Entre los miles de emigrantes se encontraban médicos, cirujanos y practicantes, tanto liberales como carlistas, que reanudaron el ejercicio de su profesión en países como Uruguay o Argentina, como ejemplifica el caso de Cayetano Garviso (Gil Pérez, 2001).

En contraste con esta capacidad de los vascos de articular 'por encima' un espacio y unas redes propios que escapaban de la sanidad militar española, el caso del Campo de Gibraltar reflejaba un fenómeno de carácter opuesto. Esta comarca, situada en la vecindad del Peñón de Gibraltar, ocupado por Gran Bretaña desde 1705 y que abarcaba aproximadamente un cuarto de la provincia de Cádiz, constituía una formación peculiar dentro del entramado administrativo español. Su origen se remontaba a la conquista británica del Peñón y se derivaba de una decisión personal del rey Felipe V. Este monarca concentró un fuerte contingente de tropas en las proximidades de Gibraltar con vistas a su reocupación y dispuso que los antiguos habitantes expulsados y reagrupados en las poblaciones de San Roque, Algeciras y Los Barrios fueran considerados como "mi ciudad de Gibraltar residente en su campo" (Montero, 1860, p. 326). Aunque el Comandante General, residente primero en San Roque y desde 1805 en Algeciras, dependía en teoría del Gobierno Militar de Cádiz, en la práctica actuaba con autonomía y solo dependía de las autoridades centrales como si fuera un Capitán General. Con el tiempo, asumió también las competencias de Hacienda y desde 1852 adquirió funciones de gobernador civil, con lo que concentraba en sus manos todo el 
poder civil y militar en la zona (Montero, 1860). A pesar de que los límites del campo se fueron ampliando y las atribuciones de su jefe expandiendo, rara vez se consignaba oficialmente su existencia en la legislación.

Respecto a la sanidad militar, ninguno de los reglamentos aprobados durante el periodo isabelino hizo referencia al Campo de Gibraltar. No obstante, en Algeciras funcionaba un hospital militar 'nato del Campo', con su correspondiente director, que actuaba como jefe sanitario en la zona. Por ejemplo, José María Santucho Marengo, quien habría de convertirse en director general entre 1866 y 1868, estuvo al mando de dicho hospital durante cinco años (¿1839-1844?) (Hernández Giménez, 1990). De Algeciras dependían los médicos de los regimientos estacionados en el Campo, cuyo número fue disminuyendo al tiempo que se reducía la guarnición, aunque en este periodo ésta aún se elevaba a varios miles de hombres. Igual que sucedía con la administración militar en general, la Sanidad Militar del Campo fue asumiendo competencias de la sanidad civil, dada la práctica ausencia de instituciones benéficas en la zona.

La existencia de facto del Campo de Gibraltar y la particular concentración de competencias por parte de sus autoridades militares con carácter personalista reflejaba que una amplia zona del sur de la península escapaba de la organización militar general y sanitaria. Pero, al contrario que los vascos, lo hacía 'por debajo'. La débil presencia de las estructuras militares en Andalucía y Granada se agravaba por la ocupación británica de Gibraltar que ejercía un efecto de atracción en competencia con las autoridades españolas. La ocupación británica del Peñón no solo se fue aceptando como algo irreversible (ya no hubo más 'sitios' como los del siglo XVIII), sino también susceptible de ir extendiéndose territorialmente, como lo fue en varias ocasiones durante este periodo (Cordero, 1960). El desarrollo del enclave se tradujo en la creación de un organismo sanitario, denominado primero 'los comisarios sanitarios' y posteriormente el 'consejo sanitario' de Gibraltar, que se encargaba en la práctica de todas las medidas sanitarias del Peñón. En la práctica, sus medidas, especialmente en caso de epidemias como las de cólera de 1858 y 1865, afectaban no solo a la población gibraltareña sino también a la del Campo y más allá (Montero, 1860). Por todo ello, el Comandante General del Campo fue asumiendo también competencias sanitarias civiles como medio de frenar el creciente 'impacto' de las medidas tomadas en el Peñón. No obstante, cuanto mayor se hacía la extensión del Campo y la autoridad de su jefe militar, mayor era en realidad la vulnerabilidad a la influencia gibraltareña.

Por otra parte, la presencia militar directa de Gran Bretaña en el Peñón era inseparable de la desestructuración social que persistió 
12 Real orden determinando los hospitales militares en que ha de establecerse el servicio por administración directa y los que han de suprimirse. Madrid, 5 de junio de 1854 .

Colección Legislativa de España, 2음

cuatrimestre, p. 121-2. durante todo este periodo en amplias zonas de Andalucía y Granada. El contrabando constituyó tradicionalmente la principal fuente de ingresos de Gibraltar y proporcionaba a una cierta parte de la población andaluza y granadina, reacia a o sin posibilidad de integrarse socialmente, tanto armas como diversos productos (tabaco, textiles) con los que ganarse la vida y mantenerse 'al margen de la ley'. La existencia de grupos armados al margen del ejército y de la Guardia Civil (creada en 1844) reflejaba la deficiente extensión de las estructuras militares en esta zona del país y obligaba a mantener a los relativamente reducidos contingentes de tropas de las capitanías de Andalucía y Granada en un estado de 'pseudocampaña'. La posición del Campo de Gibraltar era estratégica dentro de las rutas de los bandoleros-contrabandistas por lo que una de sus principales funciones y justificaciones consistía en la represión de sus actividades.

Aunque el número de andaluces y granadinos en la sanidad militar fue importante durante este periodo (los directores generales García-Briz y Santucho eran de Málaga; Bastarreche, de Cádiz), en realidad, era menor del que habría correspondido a la población de ambas zonas. Hasta 1854 persistió una especie de 'línea' de hospitales militares que seguía la divisoria entre los distritos de Andalucía y Granada. ${ }^{12}$ Esta línea empezaba en el hospital de Córdoba y seguía por los de Écija, Osuna y Medinasidonia hasta el de Algeciras. Todos ellos debieron tener su razón fundamental en las actividades del ejército en relación con el bandolerismo-contrabando.

\section{¿Dentro o fuera del imperio? La sanidad militar en Filipinas}

Hasta ahora, al analizar la configuración imperial de la sanidad militar española no se ha hecho mención a Filipinas. La razón es que su situación a mediados del siglo XIX reflejó de forma ejemplar la debilidad de la organización imperial española, aunque por razones opuestas a las que se señalaron para el caso de Cuba. Si la Antilla española tuvo un peso 'excesivo' en el conjunto de la sanidad militar, el del archipiélago filipino fue sin duda demasiado pequeño. Formalmente, los desarrollos de la organización sanitaria militar en este territorio dieron lugar a lo más parecido a un modelo colonial que se pudo elaborar dentro de todo el imperio español en este periodo. Sin embargo, la extrema modestia de los mismos limitó al mínimo cualquier repercusión en la península e incluso en el propio lugar de aplicación, hasta el punto de que el archipiélago parecía más fuera que dentro del imperio.

En Filipinas, los médicos militares españoles actuaron de forma unificada sin diferencias según su lugar de origen. Es significativo, por ejemplo, que la subinspección del distrito fuera ocupada durante casi todo este periodo por dos médicos catalanes, Antoni 
13 Expediente personal de Antonio Codorniu Nieto, sección 1, legajo C2977.
Codorniu Nieto, entre 1844-46 y 1849-59 (figura 4), y Josep Brangulí i Doménech, entre 1859 y $1865 .{ }^{13}$ La propia trayectoria de ambos antes y después del destino en Filipinas reflejó un mayor grado de integración dentro de la sanidad militar española que la del grupo catalán en general. Así, Codorniu se formó en el Colegio de Cirugía de San Carlos de Madrid y sirvió en el hospital militar de dicha plaza antes de embarcar para Manila. Posteriormente, fue nombrado subinspector de Castilla La Nueva y participó en la guerra de África, para incorporarse después a la Junta Superior Facultativa. Por su parte, Brangulí había sido destinado con anterioridad al Hospital Militar de Badajoz y como subinspector del distrito de Canarias. Sin embargo, el escaso número de facultativos del ejército en Filipinas (12 en 1846 y 23 en 1859) impedía que esta dinámica contribuyera significativamente a la integración peninsular y en el imperio en general.

El ritmo de circulación de médicos peninsulares hacia Filipinas fue demasiado lento. No parecen indicarlo así ni el periodo mínimo de estancia establecido por ley, que era de seis años como en Cuba, ni el número de subinspectores del periodo 1844-1868, que fue el mismo que en la Antilla española. No obstante, teniendo en cuenta el carácter fuertemente 'insalubre' del territorio para los europeos y la voluntad de extensión del dominio español, lo lógico habría sido organizar una rotación más frecuente y de menos duración que para Cuba. Por el contrario, los médicos militares solían sobrepasar a menudo la duración mínima, como Antoni Codorniu, que permaneció 15 años en Manila o Rufino Pascual y Torrejón, que estuvo allí entre 1854 y 1862. Como resultado, la mortalidad fue alta y, por ejemplo, Codorniu hubo de suceder por dos ocasiones a subinspectores que fallecieron en su puesto, José Fernández de Ceballos en 1844 y Joaquín Ponce Beato en 1849. Podría decirse que el destino en Filipinas no tenía un carácter de mera etapa, pero tampoco de asentamiento, sino más bien de 'aventura' con el consiguiente perjuicio para el funcionamiento general de la sanidad militar.

Por otro lado, la posibilidad de que los criollos constituyeran una sanidad militar independiente de las autoridades españolas fue mínimo debido a su escaso número y a su colaboración generalizada dentro de las instituciones coloniales. Tampoco hubo amenaza por parte de otras potencias europeas con presencia en la zona como Gran Bretaña, Francia y Holanda, a pesar de la presencia no extraña de médicos extranjeros en el archipiélago. En contraste, casi podría decirse que las pretensiones coloniales españolas estuvieron en desventaja, o al menos hubieron de afirmarse reiteradamente frente a las de otras sociedades de la región. La definición de una 'fisonomía insular' en Filipinas al modo de Cuba estuvo muy lejos de lograrse en este periodo porque los españoles ni siquiera tenían asegurada la primacía en el archipiélago. 


\section{TOPOQRARIA MRDIGA}

$\mathrm{DE}$

\section{LAS ISLAS FILIPINAS}

POR EL DOCTOR

\section{ANTONIO CODORNIU Y NIETO,}

Subinspector dbédico de primero dase del $\Theta_{\text {ucupo }}$ ie Saridad dlbilitax, y Gefer del mismo Euexpo en aquellas Jslas.

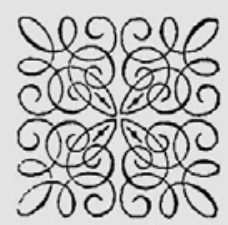

MADFID : 185\%.

$-1040$

IMPRENTA DE D. ALEJANDRO GOMEZ FUENTENEBRO, calle de la Colegiata, núm. 6. 
Para ello hay que considerar que el número de españoles y criollos era aproximadamente de 5.000 para una población nativa de entre 3 y 5 millones de habitantes (Regodón, 2002, p. 23). En comparación, el número de emigrantes chinos (conocidos como sangleyes) era de 9.000 en 1854 y aumentó hasta los 50.000 a finales de siglo (Regodón, 2002). En el sur del archipiélago, la población del Sultanato musulmán de Joló debía ser aún mayor. Por otra parte, también hay que señalar que la presencia española en el archipiélago se limitaba en esta época a un sector de Luzón, Cebú y una serie de enclaves costeros en Mindanao y en otras islas. La mayor parte del territorio y de la población estaban fuera del alcance de los españoles. La distribución geográfica de los sangleyes seguía la de los españoles mientras que la población musulmana se concentraba en el sur del archipiélago.

En estas circunstancias, los españoles debían no ya tratar de integrar estos grupos sino antes de nada asegurar su propia supremacía frente a ellos. Por ejemplo, no parece extraño que, según Regodón, las autoridades españolas siempre mostraran desconfianza hacia los sangleyes, "sospechando que con el tiempo pudiesen tener la tentación de adueñarse del país" (Regodón, 2002, p. 24). No era una cuestión solo de su número considerable, sino también de su alto nivel de organización y del mantenimiento de sus usos y cultura. Para neutralizarlos se siguió una política de restricción de la inmigración y de segregación sistemática de la administración y de las instituciones que impidió cualquier participación en el ejército y en la sanidad militar. El número de médicos de tradición china que asistían a los sangleyes debió ser más numeroso que el de médicos españoles y pudo mantenerse gracias a la práctica privada o el servicio a la comunidad, aunque también "gozaban de un cierto prestigio y clientela entre los europeos" (Regodón, 2002, p. 31). Sus contactos con la China continental para proveerse de instrumental o farmacopea debieron ser frecuentes, como lo eran los de la comunidad en general. En todo caso, dado que los sangleyes solían seguir los modestos avances del ejército español en el archipiélago, no parece descabellado pensar que algunos de esos médicos pudieran prestar sus servicios a los soldados o se les permitiera asistir a la población nativa con funciones de atracción, siempre sin vinculación formal con la sanidad militar.

Frente a esta firmeza 'pacífica' hacia los sangleyes, los enfrentamientos con los musulmanes fueron constantes. Las autoridades españolas se quejaban constantemente de los actos de 'piratería' llevados a cabo por los 'moros' de Joló o de otras islas meridionales, pero lo cierto es que la presencia musulmana en la zona estaba muy asentada y extendía su influencia a una parte de la isla de Mindanao, la segunda en extensión del archipiélago. Para contrarrestarla, en 1851 se llevó a cabo una expedición militar de 
cierta envergadura contra el Sultanato de Joló, en la que Antoni Codorniu actuó como jefe sanitario (Massons, 1994, v. II, p. 204), aunque los resultados fueron más bien escasos. Como parte del enfrentamiento general, la competencia de los médicos musulmanes se veía como una amenaza para la supremacía de la medicina española, sin que hubiera aparentemente puntos de contacto como en el caso de los médicos chinos.

En ninguno de los dos casos se pudo o se quiso integrar un personal que habría podido ser de enorme ayuda para la extensión del sistema sanitario español. Realmente, su presencia era tan importante y autónoma que podían aspirar a sustituirlo. Por otra parte, sin ni siquiera asegurarse una posición de dominio clara en Filipinas, parecía utópico o descabellado extender la sanidad militar a otras posesiones legales de España en la región, como las islas Carolinas y las Marianas, o bien emprender nuevas empresas coloniales como se intentó con la expedición a Cochinchina en 1859.

En otro orden de cosas, se dieron en este periodo los primeros pasos hacia la constitución de un ejército colonial que posteriormente sería conocido como "Ejército Indígena de Filipinas" (Massons, 1994, v. II, p. 203). La enorme mortalidad que solían padecer los regimientos enviados desde la península, unida a la enorme dificultad de mantener una comunicación constante (la distancia desde España era de 24.000 kilómetros y, al no existir todavía el canal de Suez, el viaje llevaba unos cinco meses); todo ello, decimos, llevó a incorporar soldados nativos en las filas del ejército, generalmente de las zonas donde la presencia española era más sólida. En la expedición a Joló debieron constituir buena parte de los más de 3.000 hombres movilizados, a los que se añadieron además otros 1.000 sin relación formal con la milicia. Carecemos de información acerca de la asistencia que recibían estos hombres y no es descartable que llevaran consigo sus propios sanadores. Cuando en 1869 se creó la Brigada Sanitaria de Filipinas, sus integrantes fueron todos nativos, salvo cuatro mandos españoles (Massons, 1994, v. II, p. 200). Sin embargo, el alcance de estas medidas fue insignificante en cuanto a la población y los territorios o etnias involucrados, por lo que hablar de un ejército 'colonial filipino' o de una sanidad militar 'colonial filipina' se antoja francamente exagerado.

Para terminar esta breve perspectiva, cabría decir que el lugar del distrito de Filipinas en el conjunto de la sanidad militar imperial fue bastante secundario en cuanto a desarrollo administrativo o institucional. Como ya se señaló anteriormente, el deficiente estado de los hospitales militares del archipiélago fue consignado en un informe del Ministerio de Estado en 1856. El hospital militar intramuros de Manila, una fundación del siglo XVI, estaba en aquellas fechas en tan penoso estado que hubo que trasladar sus 
14 Las 'expediciones militares' incluyeron, por orden cronológico, las de Cochinchina (1859), Marruecos o Guerra de África (1859-1860), Santo Domingo (1861-1865) y México (1862), a las que se añadió una de carácter naval conocida como la Guerra del Pacífico (1866) (Marín, 2005). enfermos al Hospital de San José o de San Juan de Dios de Cavite, que actuaba también en parte como hospital de la Armada. En realidad, los proyectos de reforma del hospital habían comenzado en 1844, pero no sería hasta 1886 cuando entrara en funcionamiento tras innumerables demoras e incluso haber sido derribado el edificio en construcción por un ciclón en 1882 (Regodón, 2002, p. 63). Aparte, solo había dos pequeños hospitales militares en Cebú y en Pollock (Mindanao).

\section{Crecer o fragmentarse. La sanidad militar peninsular ante la Guerra de África}

A pesar de su debilidad en el contexto internacional, el imperio español alcanzó un cierto equilibrio que le permitió intentar en un momento dado extender los espacios metropolitano y colonial. Este intento coincidió con el gobierno de la Unión Liberal encabezado por el general Leopoldo O'Donnell, entre 1858-1866, y ha sido calificado como 'política de expediciones militares' o 'política de prestigio' para indicar tanto el carácter de predominante de sus actividades como sus escasos resultados prácticos (Jover Zamora, 1992). No fue desconocido para sus protagonistas que esta expansión se acompañaba al mismo tiempo de una cierta consolidación interna de las estructuras peninsulares y ultramarinas y algunos quisieron ver en ello su objetivo principal. Ambos procesos eran dos caras de la misma moneda y, por ello, la unidad interna fue tan frágil como efímera (García Balañá, 2002).

La campaña de Marruecos o Guerra de África constituyó la vertiente metropolitana de ese esfuerzo expansivo y de cohesión. ${ }^{14}$ Este conflicto tuvo lugar en un momento en que Europa parecía volver a sus seculares enfrentamientos bélicos con las guerras de Crimea (1853-1856), Italia (1859), Austro-prusiana (1866) y finalmente, Franco-prusiana (1870-1871). A pesar de la participación simbólica y cuasi 'clandestina' en Crimea, a través del 'viaje a Oriente' del general Prim (De Diego, 2003), y de una fantasmal 'Legión ibérica' que pretendió apoyar a Garibaldi en Italia en la década de 1860 (García Balañá, 2002), lo cierto es que España no tenía la fortaleza militar suficiente como para participar en estos conflictos europeos. En este sentido, la guerra con Marruecos fue lo más parecido que pudo permitirse. A pesar de la retórica agresivamente colonialista empleada para 'orientalizar' o 'barbarizar' al país magrebí, atacarlo era una empresa doblemente difícil, tanto por el relativo grado de desarrollo de su ejército, como por los poderosos intereses europeos que se concentraban en la zona.

Por otra parte, como señala Alberto García Balañá, las guerras de este periodo tuvieron una dimensión interna muy clara, en un sentido 'reformista' que abriera 'socialmente, las administraciones civil 
15 Ejército de África. Estado del personal de Sanidad Militar, Memorial de Sanidad del Ejército y Armada, Años 1859-1860, p. 663-7. y militar' a las clases medias y obreras, pero también 'nacionalista', que reforzara la cohesión o diera realidad a las aspiraciones patrióticas de signo liberal, incluida la 'nación en armas' (García Balañá, 2002). En el caso español, los movimientos en este sentido fueron modestos, simbolizados por el frágil equilibrio de la Unión Liberal y el gobierno personalista de O'Donnell. El relativo consenso interno permitió al menos intentar un fortalecimiento de la administración central y una profundización del modelo de ejército instaurado por Narváez durante la década de 1840, así como buscar una mayor identificación de zonas como Cataluña con el proyecto nacional (Jover Zamora, 1992; Puell, 2000; García Balañá, 2002).

Respecto a lo primero, y ya en el ámbito de la sanidad militar, la campaña marroquí se tradujo en el refuerzo de la presencia española en Marruecos. Por primera vez, los médicos militares pudieron actuar más allá de los enclaves costeros (Ceuta, Melilla, Islas Chafarinas, Peñón de Vélez de la Gomera y Peñón de Alhucemas) en el interior del territorio marroquí. Así, durante los combates se instalaron en Tetuán dos pequeños hospitales militares y en el periodo de ocupación (1861-1863) quedó al cuidado de las tropas el médico catalán Sebastián Cabanes i Matarrodona (Massons, 1994). La guerra supuso también un estímulo para los enclaves españoles. Los campos exteriores de Ceuta y Melilla se ampliaron, al menos legalmente. Ceuta dejó de depender del distrito de Andalucía y se convirtió en la Capitanía General de África, con su propio jefe sanitario. Todos los enclaves fueron declarados puertos francos y con el tiempo se establecieron en ellos hospitales y enfermerías militares o se reforzaron los existentes (Martínez Antonio, 2005b).

Evidentemente, el resultado fue mucho menor de lo anunciado, teniendo en cuenta los gastos sanitarios de la campaña y el hecho de que participaran en ella casi un centenar de médicos militares. ${ }^{15}$ La oposición de Gran Bretaña a la ocupación de Tánger fue decisiva en este sentido. Francia no pudo oponerse directamente, aunque el mismo año 1859 había enviado una expedición militar al este marroquí desde el Oranesado. Pero también es cierto que Marruecos desplegó iniciativas que contribuyeron a reducir el éxito español. Diplomáticamente, el Sultán manejaba las rivalidades europeas en provecho de la soberanía del país. Militarmente, tanto Muley Abdehrraman (1822-1859) como Muley Mohammed (1859-1860) comenzaron un proceso de reforma del ejército y de su servicio sanitario conocido como nizam (nuevo orden), paralelo a los que se llevaban a cabo en el Imperio Otomano o Egipto (Rollman, 1983; Martínez Antonio, 2005b). En este periodo, un número de médicos militares marroquíes fueron enviados a las escuelas de medicina militar de Estambul o El Cairo para recibir su formación y entrar al servicio de las nuevas unidades askar. Se promovieron también intercambios de obras científicas con esos países, muchas de 
contenido militar (Moussaoui \& Roux Dessarps, 1995). Durante la Guerra de África, Marruecos recibió asesoramiento técnico británico desde Gibraltar, que pudo haber incluido aspectos sanitarios. En años posteriores, un cierto porcentaje de los militares enviados al Peñón para adiestramiento militar fueron formados como auxiliares sanitarios (Pennell, 2000).

En lo que se refiere al ámbito interno, el grado de unidad de la sanidad militar en su actuación en Marruecos fue mayor de lo habitual. Por ejemplo, los más de 30 médicos catalanes estuvieron distribuidos bastante homogéneamente por las cuatro divisiones de que constó el ejército de operaciones. La jefatura sanitaria recayó también en un catalán, León Anel Sin, probablemente por su relación personal con el general O’Donnell, aunque enfermó y hubo de ser sustituido por José María Santucho primero y Antoni Codorniu después (Massons, 1994, v. II, p. 222). Al mismo tiempo, no obstante, hubo una participación catalana más explícitamente definida que nunca a través de los Voluntaris Catalans comandados por Prim. Los 500 voluntaris fueron asistidos por 30 médicos reclutados y pagados como ellos por la Diputación de Barcelona, la cual además organizó la instalación de un hospital en el Campo de Gibraltar, dirigido por José Esteva Vidal (Calpena \& Junqueras, 2003, p. 166; Massons, 1994, v. II, p. 223). La participación de los voluntaris y sus médicos suponía que el sector progresista o 'mesocrático' de la sociedad catalana que hasta entonces solo había participado en la creación de las milicias provinciales y cuerpos francos en diferentes momentos (el más reciente, 1856) se articulaba ahora de forma coordinada con el ejército regular. En Marruecos también actuaron voluntarios de la Diputación de Vizcaya, que dispusieron de sus propios médicos.

Por otro lado, la Guerra de África se acompañó de una serie de desarrollos administrativos e institucionales de la sanidad militar peninsular. En 1860, se creó en Madrid el parque central de material sanitario, encargado del almacenamiento y distribución de botiquines, instrumental o medios de transporte de heridos a todos los distritos. Ese mismo año se constituyó en Ceuta la primera 'compañía sanitaria' que, aunque fue disuelta al fin de la guerra, constituyó el precedente de las compañías y brigadas que habrían de crearse a lo largo de la década. También se aceleró la reforma de los cuarteles de acuerdo con nuevos criterios higiénicos, así como la construcción de nuevos hospitales o la recolección de datos estadísticos sobre el movimiento de enfermos en hospitales y regimientos (Martínez Antonio, 2005a). Sin embargo, no llegaron a funcionar en este periodo ni la escuela de medicina militar, ni el laboratorio de medicamentos, ni tampoco los médicos lograron hacerse con el control técnico de los asuntos sanitarios frente a los jefes militares. 
En definitiva, el grado de expansión y cohesión proporcionado por la Guerra de Âfrica fue pequeño y no duró demasiado. La imagen que quedó de la sanidad militar durante la guerra fueron los miles de enfermos de cólera que tuvieron que ser evacuados por barcos hospitales o simples embarcaciones mercantes a una gran parte de los hospitales militares peninsulares (Serrallonga, 1998). En el contexto de la competencia internacional, no crecer significaba fragmentarse. Solo unos años más tarde, las estructuras sanitarias levantada por los independentistas en Cuba y por los carlistas y cantonalistas en España hicieron peligrar la existencia misma de la sanidad militar en todos sus escenarios. Una vez superados estos problemas, la expansión de la sanidad militar comenzaría a reorientarse hacia África, aunque para entonces ya se había perdido definitivamente la posición de fuerza que se había tenido en Marruecos en periodos anteriores.

\section{Conclusión: La trama visible del imperio}

El periodo isabelino constituyó una nueva fase histórica en la trayectoria secular de la acción colectiva frente a la enfermedad en el Imperio español. Bajo el signo de la pérdida de las posesiones continentales en América en las primeras décadas del siglo XIX, la sanidad imperial española se encontró en una posición sustancialmente más débil en el contexto internacional y con graves problemas de fragmentación interna. Esto se tradujo, por una parte, en un desarrollo preferente de las ramas marítima y militar frente al resto de componentes sanitarios, de forma que aquéllos llegaron a constituir los únicos con verdadero alcance imperial. Por otra parte, en la sanidad marítima y en la militar - de ésta última es de la que nos hemos ocupado - la implantación de un modelo 'sanitarista' suficientemente estable para sustituir al previo de 'policía médica' solo fue posible a partir de la articulación de un eje transimperial Madrid-La Habana en el que esta última ciudad parecía constituir en múltiples aspectos el auténtico centro imperial. Esta traslocación del núcleo de la sanidad militar imperial revelaba el papel crucial del escenario ultramarino cubano para el equilibrio del sistema en su conjunto.

No obstante, esta conexión era demasiado estrecha: la debilidad del sistema sanitario militar se reflejó en la imposibilidad de constituir un espacio metropolitano y unos espacios coloniales 'típicos', suficientemente separados entre sí. Del mismo modo tampoco fue posible constituir un espacio metropolitano y unos espacios coloniales suficientemente cerrados y homogéneos en sí mismos. La imposibilidad de evitar las influencias externas y las divisiones internas se tradujo en fenómenos como la participación diferenciada de los catalanes en el eje transimperial, la trayectoria separada de 
las Provincias Vascas y el Campo de Gibraltar en la península, de los médicos criollos y los sanadores culíes y de raza negra en Cuba y de los médicos sangleyes, los médicos musulmanes y los sanadores nativos en Filipinas. Este último territorio estuvo todavía durante este periodo más fuera que dentro del imperio, en claro contraste con la posición de Cuba y Puerto Rico. Finalmente, durante un breve periodo entre finales de los años 50 y principios de los 60 pareció que el sistema había alcanzado un equilibrio que le permitía intentar un cierto refuerzo de su articulación imperial. Sin embargo, como quedó patente en el caso de Marruecos (y también en los de México y Cochinchina), dicho equilibrio fue breve en su duración y tuvo escasos resultados prácticos.

Podría parecer que el análisis que se ha hecho en este trabajo de la particular configuración de la sanidad militar en el imperio español solo confirmaría, por defecto, los modelos interpretativos habituales basados en la dicotomía metrópoli-colonias. Sin embargo, en nuestra opinión, el análisis del imperio español es útil para probar la validez de la interpretación imperial porque permite observar de forma especialmente explícita las conexiones transversales que en otros imperios estuvieron más disimuladas. En el caso español, la trama del imperio fue especialmente 'visible' y ello nos permite suponer su existencia generalizada en otras sociedades imperiales de la época, indudablemente con características distintas pero solo diferentes en el grado de 'visibilidad'.

En definitiva, creemos que la aplicación de la perspectiva imperial ha permitido entender mejor la evolución histórica de la sanidad militar española tanto en la península como en ultramar e identificar la iniciativa de diversos grupos y territorios que no aparecían en el relato oficial ni en la historiografía. La brevedad de este trabajo no ha permitido una gran dosis de detalle, pero como se señaló al principio, la cuestión fundamental era más el esfuerzo de síntesis, el planteamiento de las cuestiones propias del nivel de análisis imperial como tal, que la descripción en detalle, aunque en un trabajo historiográfico siempre haya un equilibrio entre ambos y así hayamos tratado de hacerlo en éste. Creemos que un mayor grado de complejidad suele llevar consigo un mayor grado de realidad.

\section{BIBLIOGRAFÍA}

AA.V.

1995

Ancheta Niebla, E. 2003

Anderson, W. $2003 a$
Catalunya i Ultramar. Poder i negoci a les colònies espanyoles (1750-1914). Barcelona: Museu Marítim.

Historia de la enfermería en Cuba. La Habana: EcMed.

How's the empire? An essay review. Journal of the History of Medicine and Allied Sciences, v. 58, p. 459-65. 
Anderson, W. $2003 b$

Anderson, W. 1998

Bashford, A. 2000

Busquets, J. 1984

Calbet i Camarasa, J. M.;

Corbella i Corbella, J. 1981-1983

Calpena, E.;

Junqueras, $\mathrm{O}$. 2003

Cañizares-Esguerra, J. 2005

Cañizares-Esguerra, J. 2003

Castells, L. 2003

Cayuela Fernández, J. G. 1993

Clara, J. et al. 1995

Cooper, F.; Stoler, A. L. (ed.)

1997

Cordero Torres, J. M. 1960

De Castro Antolín, M. L. 1994

De Diego, E. 2003

Delgado García, G. 2004

Delgado García, G. $1996 a$

Delgado García, G. 1996b

Del Pino y de la Vega, $M$. 1963
The cultivation of whiteness: Science, health and racial destiny in Australia. New York: Basic Books.

Where is the postcolonial history of medicine? Bulletin of the History of Medicine, v. 72, p. 522-30.

Is white Australia possible? Race, colonialism and tropical medicine. Ethnic and Racial Studies, v. 23, n. 2, p. 248-71.

El militar de carrera en España.

Barcelona: Ariel.

Diccionari biogràfic de metges catalans. 3 v. Barcelona: Fundació Salvador Vives Casajuana.

Guerres dels catalans.

Barcelona: Pòrtic.

Iberian Colonial Science.

ISIS, v. 96, p. 64-70.

Spanish America: From baroque to modern colonial science.

In: Porter, R. (ed.) The Eighteenth Century, v. 4 of Lindberg, D.; Numbers, R. (ed.) The Cambridge history of science.

Cambridge: Cambridge University Press, p. 718-38.

La abolición de los fueros vascos.

Ayer, v. 52, p. 117-50.

Bahía de ultramar. España y Cuba en el siglo XIX.

El control de las relaciones coloniales. Madrid: Siglo XXI.

Exércit $i$ societat a la Catalunya contemporània.

Girona: Cecle d'Estudis Històrics i Socials.

Tensions of empire. Colonial cultures in a bourgeois world.

Berkeley: University of California Press.

Fronteras hispánicas.

Madrid: CSIC.

Fernando Poo y los emancipados de La Habana.

Estudios Africanos, v. VIII, n. 14-15, p. 7-19.

Prim. La forja de una espada.

Barcelona: Planeta.

La medicina china y su presencia en Cuba. Cuadernos de Historia de la Salud Pública, v. 95. Disponible en: bvs.sld.cu/revistas/his/vol_1_97/hissu197.htm

La salud pública en Cuba durante el periodo colonial español.

Cuadernos de Historia de la Salud Pública, v. 81, p. 1-7. Disponible en: bvs.sld.cu/revistas/his/vol_1_96/hissu196.htm

La salud pública en Cuba durante el periodo colonial español.

Cuadernos de Historia de la Salud Pública, v. 81, p. 1-9. Disponible en: bvs.sld.cu/revistas/his/vol_1_96/hissu196.htm

Apuntes para la historia de los hospitales de Cuba (1523 a 1899).

Cuadernos de Historia de la Salud Pública, v. 24. Monográfico. 
Elena, A.; Ordóñez, J. Science, technology and the Spanish colonial experience in the 2000

Enciclopèdia Catalana 1997

Fradera, J. M. 1999

Fradera, J. M. 1987

García Balañá, A. 2002 nineteenth century. Osiris, 2nd Series, v. 15 [Nature and Empire: Science and the Colonial Enterprise], p. 70-82.

La gran transformació 1790-1860. (v. 6) Barcelona.

Gobernar colonias.

Barcelona: Península.

Indústria $i$ mercat. Les bases comercials de la indústria catalana moderna. Barcelona: Crítica.

Patria, plebe y política en la España isabelina: la guerra de África en Cataluña (1859-1860). In: Martín Corrales, E. (ed.) Marruecos y el colonialismo español (1859-1912). De la guerra de África a la penetración pacífica. Barcelona: Bellaterra. p. 13-78.

Gil Pérez, J. 2001

La obra de Cayetano Garviso (1807-post. 1871). Cirujano vasco-navarro liberal en América. Barcelona: Seminari Pere Mata (Universidad de Barcelona).

González Calleja, E. 1992

De guardia rural a milicia antiobrera: la trayectoria histórica del Somatén catalán durante la Restauración (1875-1923). En: Actas del Congrès Internacional d'Història. Catalunya i la Restauració. Manresa: Centre d'Estudis del Bagés. p. 51- 60.

Granjel, L.; Goti, J. L. 1983

Guerra, F. 1994

Guerra, F. 1975

Historia del hospital de Basurto.

Bilbao: s.n.

El hospital en Hispanoamérica y Filipinas (1492-1898).

Madrid: Ministerio de Sanidad y Consumo.

Manuel Codorniu Ferreras (1788-1857). In: AA.VV. Actas del IV Congreso de la Sociedad Española de Historia de la Medicina. Granada: Secretariado de Publicaciones de la Universidad de Granada. p. 321-7.

Guerra, F.

Harrison, M. 2005

Harrison, M. 1996

Manuel Codorniu Ferreras (1788-1857). Azares de un médico liberal en la sociedad hispanoamericana del siglo XIX. Medicina e Historia, 1르 época, v. 30.

Science in the British Empire.

ISIS, v. 96, p. 56-63.

A question of locality: the identity of cholera in British India, 1860-1890. In: Arnold, D. (ed.) Warm climates and western medicine. The emergence of tropical medicine, 1500-1900. Amsterdam/Atlanta: Rodopi. p. 133-59

Haynes, D. M. 2001

Haynes, D. M. 2000

Imperial Medicine: Patrick Manson and the conquest of tropical disease. Philadelphia: University of Pennsylvania Press.

Framing tropical disease in London: Patrick Manson, Filaria perstans and the Uganda Sleeping Sickness epidemic, 1891-1902. Social History of Medicine, v. 13, p. 467-93.

Hernández Giménez, J. Medicina militar e historia de la medicina. 1990

Medicina Militar, v. 46, p. 96-114.

Hobsbawm, E.

La era del imperio 1875-1914.

1998

Barcelona: Ed. Crítica.

Jardí, E. 1998

El desastre colonial i Catalunya.

Barcelona: Pòrtic.

Jover Zamora, J. M. La civilización española a mediados del s. XIX. 1992 
Lafuente, A. 2000

Latour, B. 1997

Lefevbre, P. (dir.) 1987

Kamen, $\mathrm{H}$. 2003

Marín, F. A. 2005

Marset, P.;

Sáez Gómez, J. M. 1998

Martínez Antonio, F. J. $2005 a$

Martínez Antonio, F. J. 2005b

Massons, J. M. 1994

McAllister, W. B. 1993

Molero Mesa, J.; Jiménez Lucena, I. 2000

Montero, F. M. 1860

Moratinos Palomero, P. (coord.) 1988

Moreno Fraginals, $M$. 2002

Moreno Fraginals, M.;

Moreno Masó, J. J. 1993

Moussaoui, D.;

Roux-Dessarps, M. (ed.) 1995

Parrilla Hermida, M. 1980

Pennell, C. R. 2000

Pérez Garzón, J. S. 1978

Pimentel, J. 2000

Porter, D. $1999 a$
Enlightenment in an imperial context: local science in the late eighteenthcentury Hispanic world. Osiris, v. 15, p. 155-73.

Nous n'avons jamais été modernes.

Essai d'anthropologie symétrique. Paris: La Découverte.

Histoire de la médecine aux armées.

3 v. Paris: Lavauzelle.

Imperio. La forja de España como potencia mundial.

Madrid: El País-Aguilar.

Martínez se va a la guerra. Intervenciones militares de España en el extranjero. Barcelona: Inèdita Ed.

La evolución histórica de la salud pública. In: Martínez Navarro, F. et al. (ed.) Salud pública. Madrid: McGraw-Hill Interamericana, p. 1-24.

El proceso de sanitarización en los imperios español y marroquí.

Bellaterra: Universitat Autònoma de Barcelona. Tesis doctoral.

La sanidad en Marruecos a mediados del siglo XIX.

Medicina e Historia, 4⿳亠丷⿵冂⿱⺊口灬 época, v. 2.

Historia de la Sanidad Militar española. 4 v. Barcelona: Pomares Corredor.

The debate over the reorganization of the French Military Medicine Service, 1870-1899. Essays in History, v. XXXV, p. 93-109. Disponible en: etext.virgnia.edu/journals/EH/EH35/mcall1.html

Salud y burocracia en España. Los cuerpos de Sanidad Nacional

(1855-1951). Revista Española de Salud Pública, v. 74, p. 45-79.

Historia de Gibraltar y su campo. s.l.:

Imprenta de la Revista Médica.

Hospital Militar Central 'Gómez Ulla'. 100 años de historia.

Madrid: Hospital Militar Central 'Gómez Ulla'.

Cuba/España, España/Cuba. Historia común.

Barcelona: Ed. Crítica.

Guerra, migración y muerte.

El ejército español en Cuba como vía migratoria. Gijón: Júcar.

Histoire de la médecine au Maroc et dans les Pays Arabes et Musulmans.

Casablanca: Imp. Najah El Jadida.

La dirección de Sanidad Militar.

Su primer director. Asclepio, v. 32, p. 295-302.

Morocco since 1830. A history.

London: Hurst and Co.

Milicia nacional y revolución burguesa.

Madrid: CSIC.

The Iberian vision. Science and empire in the framework of universal monarchy, 1500-1800. Osiris, v. 15.

Health, civilization, and the state. A history of public health from Ancient to Modern Times. London: Routledge. 
Porter, D.

$1999 b$

Puell de la Villa, F. 2000

Regodón Vizcaíno, Juan 2002

Ring, F.

1962

Roldán y Guerrero, R. 1958

Rodríguez Ocaña, E. 2005

Rodríguez Ocaña, E. 1994

Rodríguez Ocaña, E. 1992

Rodríguez Ocaña, E. et al.

2003

Rollman, W. J.

1983

Rosen, G. 1958

Serrallonga Urquidi, J. 1998

Stutchey, B. (ed.) 2005

Vallverdú, $\mathrm{R}$. 1986

Yáñez, C. $1992 S$
The history of public health: Current themes and approaches. Hygiea Internationalis, v. 1, n. 1, p. 9-21.

Historia del ejército en España. Madrid: Alianza Editorial.

Contribución al estudio de la medicina en las Islas Filipinas en la segunda mitad del siglo XIX. Madrid: Universidad Complutense de Madrid. Tesis doctoral inédita.

Zur Geschichte der Militärmedizin in Deutschland. Berlin: Deutscher Militärverlag.

Historia del Cuerpo de Farmacia Militar del Ejército español. Archivo Iberoamericano de Historia de la Medicina y Antropología Médica, v. 10, p. $161-80$ y $275-93$.

Salud pública en España. Ciencia, profesión y política, siglos XVIII-XX. Granada: Universidad de Granada.

De la Junta de Sanidad al Instituto de Higiene. In: AA.VV. Historia y medicina en España. Homenaje al Profesor Luis S. Granjel.

Valladolid: Consejería de Cultura y Turismo de la Junta de Castilla y León, p. 237-49.

Por la salud de las naciones.

Higiene, microbiología y medicina social. Madrid: Akal.

La acción médico-social contra el paludismo en la España metropolitana y colonial del siglo XX. Madrid: CSIC.

The 'New Order' in a pre-colonial Muslim society: Military reform in Morocco, 1844-1904. 2 v. Ann Arbor: University of Michigan. Tesis doctoral.

A history of public health.

New York: MD Publications.

La guerra de África y el cólera (1859-60).

Hispania, v. 198, p. 233-60.

Science across the European empires, 1800-1950.

Oxford: Oxford University Press.

La Milicia Nacional de Reus en el origens de la Catalunya isabelina.

Tarragona: Diputación de Tarragona.

Sortir de casa per anar a casa. Comerç, navegació i estratègies familiars en l'emigració de Sant Feliu de Guixols a Amèrica en el segle XIX.

Sant Feliu de Guixols. 